\title{
SPRAY DRIED LACTOSE BASED PRONIOSOMES AS STABLE PROVESICULAR DRUG DELIVERY CARRIERS: SCREENING, FORMULATION, AND PHYSICOCHEMICAL CHARACTERIZATION
}

\author{
ALI NASR ${ }^{1,2 *}$, MONA QUSHAWY1,3, SHADY SWIDAN ${ }^{4}$ \\ 1Department of Pharmaceutics, Faculty of Pharmacy, Sinai University, Alarish, Egypt, ${ }^{2}$ Department of Pharmaceutics, Faculty of Pharmacy, \\ Port Said University, Port Said, Egypt, ${ }^{3}$ Department of Pharmaceutics, Faculty of Pharmacy, University of Tabuk, Tabuk, Saudi Arabia, \\ ${ }^{4}$ Department of Pharmaceutics, Faculty of Pharmacy, The British University in Egypt, Cairo, Egypt \\ Email: ali.nasr@su.edu.eg
}

Received: 05 Jun 2018, Revised and Accepted: 16 Jul 2018

\section{ABSTRACT}

Objective: In the present investigation efforts were considered to optimize the different conditions for the preparation of spray dried lactose based proniosomes. The aim of this research was to investigate the feasibility of proniosomes as stable precursors for the development of niosomes as oral drug delivery system for poorly water-soluble drugs.

Methods: A total of twenty-eight plain proniosomal formulae were prepared with various surfactant-cholesterol loading ratios in each formula using spray dried lactose as a carrier. Span 20, 40, 60 and 80 were used in various molar ratios with cholesterol. Different evaluation techniques were performed to study the performance of the prepared proniosomes. The micromeritic properties of the prepared proniosomes were analyzed. The reconstituted niosomes were further evaluated for morphological characterization using transmission electron microscope (TEM), particle size analysis, zeta potential, and polydispersity index (PDI). Finally, selected proniosomal formulae were tested for stability study.

Results: The proniosomal formulae prepared using span 40 and span 60 exhibited excellent flowability while those prepared with span 20 and span 80 showed poor flow properties. TEM photographs revealed that the vesicles were discrete, spherical without aggregation. The mean vesicle size of reconstituted niosomes was found to be in the range between $(252.9 \pm 0.43-624.3 \pm 0.23 \mathrm{~nm})$ with perfect PDI values $(0.387 \pm 0.05-0.835 \pm 0.03)$. The negative values of zeta potential indicated that all prepared formulae were stabilized by electrostatic repulsion forces. Stability studies confirmed that proniosomes give a more stable system that could overcome the problems of standard niosomes. Formulae with the smallest particle size, higher surface charge values and best flow properties were selected to be loaded with poorly soluble drugs for further study.

Conclusion: The obtained results offered evidence that spray-dried lactose based proniosomes are promising stable drug delivery carriers and ready to incorporate various poorly water-soluble drugs in order to improve their limited oral bioavailability.

Keywords: Proniosomes, Spray dried lactose, Surfactant, Cholesterol, Drug delivery carrier and Bioavailability

(C) 2018 The Authors. Published by Innovare Academic Sciences Pvt Ltd. This is an open access article under the CC BY license (http://creativecommons.org/licenses/by/4.0/) DOI: http://dx.doi.org/10.22159/ijap.2018v10i5.27732

\section{INTRODUCTION}

Over the decades, the oral route remains the most preferred route of administration for drug delivery. However, a plurality of the new and present drugs taken by oral route usually face bioavailability drawbacks [1]. Different approaches have been employed for improving the dissolution profile of poorly water-soluble drugs [2].

Considerable interest has been focused on the design and formulation of new drug delivery systems. Among them, vesicular drug delivery systems are of high significance. There are different types of vesicular drug delivery systems such as liposomes, niosomes, transferosomes, ethosomes, colloidosomes, and cubosomes. Novel approaches like provesicular drug delivery systems such as proniosomes, layerosomes and ufosomes have also been developed which have higher stabilities compared to conventional and simple vesicular systems [3]. Provesicular systems can be used for prolonged and targeted drug delivery with mild side effects and also provides patient compliance by decreasing the administered dose.

Colloidal particulate drug delivery systems such as liposomes [4] or niosomes [5] are very distinguished in comparison to conventional dosage forms because these vesicular systems can act as drugcontaining reservoirs and alter the particle composition or surface to adjust the drug release or the affinity of the drug for the target site. Niosomes are nonionic surfactant vesicles which can entrap both hydrophilic and hydrophobic drugs [6]. Niosomes proved to be an alternative to liposomes because they have more chemical stability and economical as compared to liposomes. But though niosomes reveal good chemical stability, there may be drawbacks of physical instability concerning the dispersions. Similar to liposomes, aqueous niosomal dispersions may show aggregation, fusion, leakage of included drugs, or hydrolysis of encapsulated drugs, thus reducing the shelf life of niosomes [7].

So as to overcome the stability troubles concerning niosomes, proniosomes (dry niosomes) were developed. Proniosomes are dried powder, free flowable, granular product which upon dilution with water develops niosomal dispersion convenient for oral administration [8]. The niosomes formed after reconstitution is analogous to conventional niosomes, however, have uniform size [9].

Different nonionic surfactants with varying HLB were used in the preparation of proniosomes such as polyoxyethylene sorbitan esters (Tweens) [10], polyoxyethylene alkyl ethers (Brijs) and sorbitan esters (spans) [11]. It was noticed that for optimum proniosomes formulations which achieved smaller particle size, and higher entrapment efficiency is obtained within the HLB range from 1 to 8, which is the range of spans [12]. Cholesterol provides rigidity to the niosomes after the hydration of proniosomes and decreases drug leakage, thus increasing the entrapment efficiency. It also stabilizes the structure of the niosomes by inhibition of aggregate formation by exerting steric effect [13].

Different carriers are used in the formation of the dry proniosomes such as: mannitol, sorbitol, lactose and maltodextrin. The desired properties of the carrier include; non-toxicity and in vivo safety, poor solubility in the solvent of the loaded solution, free flowability, and excellent water solubility for easy and instant hydration [14]. Spray dried lactose shows optimum behavior as a carrier in proniosomal systems as it has a spherical shape and best flowability among other carriers [15].

There are the various method used for the preparation of proniosomes which include a slurry method and the spraying of 
surfactant on solid carrier [16]. There are several factors that must be controlled for the successful formulation of proniosomes. Among the factors, the concentration of surfactant, the ratio of surfactant concentration to cholesterol concentration, the type of the solid carrier and other factors related to the preparation technique such as the amount of organic solvent and the speed of stirring [17].

This research is a screening study aims to prepare plain (unloaded) proniosomes with optimized composition. Factors studied are the surfactant type and the ratio of surfactant to cholesterol. The selection of the optimum proniosomal formula allows a better understanding of the factors that governs the characteristics of the formed niosomes that can be loaded with different drugs. The aim of our work was to assure the feasibility of proniosomes as stable precursors for the development of niosomes as oral drug delivery system for drugs with low oral bioavailability.

\section{MATERIALS AND METHODS}

\section{Materials}

Cholesterol was purchased from Panreac Quimica SA, Barceolna, Spain. Span 40 (Sorbitan monopalmitate), Span 60 (Sorbitan monostearate) and Sodium Hydroxide were purchased from Oxford Laboratory Chemicals, India. Span 20 (Sorbitan monolaurate) and Span 80 (Sorbitan monooleate) were from Kermel, Chemical Pure, China. Methanol and Chloroform were purchased from Fisons
Scientific Equipment, England. Spray Dried Lactose was kindly supplied as a gift sample from Medical Union Pharmaceuticals, Egypt. Sodium Dihydrogen Phosphate was obtained from PureLab, USA. All other chemicals used were of analytical grade.

\section{Methods}

\section{Preparation of dry granular proniosomes}

Dry Proniosomes were prepared using the slurry method [18]. The composition of various proniosomal formulae is shown in the table (1). Shortly, precisely weighed amounts of lipid mixture $(300 \mu \mathrm{mol})$ consisting of different grades of spans $(20,40,60$ and 80$)$ and cholesterol at different molar ratios $(3: 1,2: 1,1.5: 1,1: 1,1: 1.5,1: 2$ and $1: 3$ respectively) were dissolved in $10 \mathrm{ml}$ of solvent mixture containing chloroform and methanol (7:3 ratio). This solution was transferred into a $100 \mathrm{ml}$ round bottomed flask and spray dried lactose (1.5 gm) was added to form slurry [19]. The flask was attached to a rotary evaporator (Heidolph, Germany) and the solvent mixture was evaporated under pressure of $600 \mathrm{mmHg}$ at a temperature of $45 \pm 2{ }^{\circ} \mathrm{C}$ and $60 \mathrm{rpm}$ until spray dried lactose appeared to be dry as a thin powder film on the flask wall [20]. After ensuring the complete removal of solvent, the resultant powder was scraped and collected. The proniosomal powder was further dried overnight in desiccators at room temperature to obtain dry, freeflowing product. The obtained proniosomal powders were stored in a tightly closed container for further characterization.

Table 1: Compositions of various spray-dried lactose based proniosomal formulae

\begin{tabular}{|c|c|c|c|c|}
\hline Formula & Surfactant & Surfactant: cholesterol & Ratio $(\mu \mathrm{mol})$ & Spray dried lactose (mg)* \\
\hline F1 & Span 20 & $3: 1$ & $225: 75$ & 300 \\
\hline $\mathrm{F} 2$ & Span 20 & $2: 1$ & $200: 100$ & 300 \\
\hline F3 & Span 20 & $1.5: 1$ & $180: 120$ & 300 \\
\hline $\mathrm{F} 4$ & Span 20 & $1: 1$ & $150: 150$ & 300 \\
\hline F5 & Span 20 & $1: 1.5$ & $120: 180$ & 300 \\
\hline F6 & Span 20 & $1: 2$ & $100: 200$ & 300 \\
\hline F7 & Span 20 & $1: 3$ & $75: 225$ & 300 \\
\hline F8 & Span 40 & $3: 1$ & $225: 75$ & 300 \\
\hline F9 & Span 40 & $2: 1$ & $200: 100$ & 300 \\
\hline F10 & Span 40 & $1.5: 1$ & $180: 120$ & 300 \\
\hline F11 & Span 40 & $1: 1$ & $150: 150$ & 300 \\
\hline F12 & Span 40 & $1: 1.5$ & $120: 180$ & 300 \\
\hline F13 & Span 40 & $1: 2$ & $100: 200$ & 300 \\
\hline F14 & Span 40 & $1: 3$ & $75: 225$ & 300 \\
\hline F15 & Span 60 & $3: 1$ & $225: 75$ & 300 \\
\hline F16 & Span 60 & $2: 1$ & $200: 100$ & 300 \\
\hline F17 & Span 60 & $1.5: 1$ & $180: 120$ & 300 \\
\hline F18 & Span 60 & $1: 1$ & $150: 150$ & 300 \\
\hline F19 & Span 60 & $1: 1.5$ & $120: 180$ & 300 \\
\hline F20 & Span 60 & $1: 2$ & $100: 200$ & 300 \\
\hline F21 & Span 60 & $1: 3$ & $75: 225$ & 300 \\
\hline $\mathrm{F} 22$ & Span 80 & $3: 1$ & $225: 75$ & 300 \\
\hline F23 & Span 80 & $2: 1$ & $200: 100$ & 300 \\
\hline F24 & Span 80 & $1.5: 1$ & $180: 120$ & 300 \\
\hline F25 & Span 80 & $1: 1$ & $150: 150$ & 300 \\
\hline F26 & Span 80 & $1: 1.5$ & $120: 180$ & 300 \\
\hline F27 & Span 80 & $1: 2$ & $100: 200$ & 300 \\
\hline F28 & Span 80 & $1: 3$ & $75: 225$ & 300 \\
\hline
\end{tabular}

*One milligram of the carrier (spray dried lactose) per $1 \mu \mathrm{mol}$ of total lipid surfactant mixture.

\section{Evaluation of the proniosomes and proniosome-derived niosomes}

\section{Micromeritic properties of powdered proniosomes}

\section{The angle of repose $(\theta)$}

The angle of repose of powdered proniosomes was measured by the funnel method. Accurately weighed amount was poured through a funnel. The height of the funnel was adjusted accurately in a way that the tip of the funnel just touches the apex of proniosomes powder. The powder was then allowed to flow through the funnel. The radius of the powder pile was measured and the angle of repose determined using the following equation [21]: $\tan \theta=\mathrm{h} / \mathrm{r}$

Where; $h=$ height of the pile, $r$ = radius of the pile

\section{Bulk and tapped density}

Two grams of powdered proniosomes was taken into a $10 \mathrm{ml}$ measuring cylinder. Former volume was observed, and then the cylinder was allowed to fall under its own weight onto a hard flat surface from a height of $2.5 \mathrm{~cm}$ at 2 -second intervals. The tapping was continued until no change in volume was remarked. Bulk and tapped densities were determined using the following equations [22]: 
$\mathrm{BD}=$ Powder weight $/$ Bulk Volume

$\mathrm{TD}=$ Powder weight/Tapped Volume

\section{Compressibility index}

The compressibility of dry proniosomes was calculated by Carr's Index as follow [23]:

Carr's Index (\%) $=[(\mathrm{TD}-\mathrm{BD}) / \mathrm{TD}] \mathrm{X} 100$

\section{Hausner ratio}

It is the ratio of tapped to bulk density. It provides an idea about the flow properties of the powder and can be determined as follow [24]:

Hausner ratio $=\mathrm{TD} / \mathrm{BD}$

Preparation of niosomes from proniosomes and morphological evaluation (Photomicroscopy)

Proniosomes were transformed to noisome by hydrating with $10 \mathrm{ml}$ distilled water at $37{ }^{\circ} \mathrm{C}$ and gentle agitation using vortex mixer (MaxiMix II, USA) for $5 \mathrm{~min}$. The formed niosomes were sonicated twice for 30 seconds using sonicator (SONICS VCX 130, USA) [25]. The niosomal dispersion was put on a glass slide, and the formed vesicles were observed at a magnification of $1000 \mathrm{x}$ through an optical microscope. The formation of vesicles was observed using an optical microscope and photomicrographs were recorded [26].

\section{Morphological characterization using TEM}

The morphology of niosomal dispersion was observed using transmission electron microscopy (JEM-2100, USA). A drop of dispersion was cleaned with phosphate buffer $\mathrm{pH} 7.4$ and put on carbon-coated 300 mesh copper grid and left for 1 minute to form a thin film. These films were then negatively stained with $2 \%(\mathrm{w} / \mathrm{v})$ phosphotungstic acid solution. After drying with air, the stained films were photographed using TEM [27]. The experiment was performed at room temperature, and micrographs were taken at suitable magnification power.

\section{Analysis of the recorded TEM images}

The size distribution of the prepared proniosomes derived niosomes was analyzed using TEM images by the software Nano Measurer 1.2.5 (Fudan University, Shangshai, China) [28].

\section{Particle size analysis and PDI determination}

A small amount of freshly prepared proniosomes derived niosomes was used to determine the particle size and PDI. The vesicle size and PDI of the resultant niosomes were measured by dynamic light scattering (DLS) using a photon correlation spectrometer (Zetasizer, Malvern Instruments LTD, UK) which analyzes the fluctuations in light scattering due to the Brownian motion of the particles. Light scattering was monitored at $25^{\circ} \mathrm{C}$ at a scattering angle of $90^{\circ}$ [29].

\section{Zeta potential determination}

Zeta potential was determined to measure the stability of reconstituted niosomes. The zeta potential of the formed niosomal dispersions was determined using Zetasizer (Malvern Instruments, UK). Samples were placed in clear disposable zeta cells, and results were noted. Charges on the vesicular surface and their corresponding zeta potential values were obtained [30].

\section{Stability studies}

Selected proniosomal formulae were examined for stability by storing them at $4{ }^{\circ} \mathrm{C} \pm 1$ (refrigeration temperature) and at $25^{\circ} \mathrm{C} \pm 2$ (room temperature) for a period of 3 mo [31]. At specific time intervals $(0,30,60$ and $90 \mathrm{~d})$, samples were withdrawn and assessed for micromeritic properties, vesicles size and zeta potential [32].

\section{RESULTS AND DISCUSSION}

Evaluation of the proniosomes and proniosome-derived niosomes

Micromeritic properties of powdered proniosomes
Micromeritic properties of proniosomal formulae were considered as an important parameter as it will affect the uniformity of dose and facility of filling into capsules. The flow properties were evaluated with the aid of angle of repose, Carr's index, and Hausner ratio. The angle of repose was found to affect the flowability of the particles. The values less than $20^{\circ}$ exhibit excellent flowability; the values between 20 and $30^{\circ}$ show good flowability; the values between 30 and $34^{\circ}$ exhibit passable flowability; while the values above $34^{\circ}$ show very poor flowability [33]. Results obtained pointed out that proniosomal formulae containing span 20 [F1, F2, F3, F4, F5, F6 and F7] and span 80 [F22, F23, F24, F25, F26, F27 and F28] which are viscous liquid surfactants have large angle of repose $(>30)$, promising poor flowability. The values obtained for the angle of repose for proniosomal formulae containing span 20 and span 80 ranged from $32.02^{\circ} \pm 0.81$ to $41.87^{\circ} \pm 1.50$, as presented in table (2). These values suggest that all proniosomal formulae containing span 20 and span 80 have passable to poor flowability. This may be due to powders cohesivity which affects the flow characteristics and occasionally causes difficulties in powder flow. On the other hand, proniosomal formulae containing span 40 [F8, F9, F10, F11, F12, F13 and F14] and span 60 [F15, F16, F17, F18, F19, F20 and F21] which are solid surfactants have small angle of repose $(<30)$, confirming good flow properties. The values obtained for the angle of repose for proniosomal formulae containing span 40 and span 60 ranged from $24.79^{\circ} \pm 0.76$ to $28.43^{\circ} \pm 1.30$. These values indicate that all proniosomal formulae containing span 40 and span 60 have good flowability.

The flow properties of the prepared proniosomal formulae were also characterized by determining both bulk and tapped densities. From these values, both the Hausner ratio and the Carr's index can be derived. Both bulk and tapped densities were determined with equations described before in the experimental part. These two parameters are related to the flow properties of the prepared powder blend [34]. Carr's index of proniosomal formulae is having span 20 and span 80 was found to be between $21.00 \pm 1.32$ and $31.38 \pm 2.39$ indicating poor flowability. However, Carr's index of proniosomal formulae containing span 40 and span 60 ranged between $11.07 \pm 2.76$ and $19.62 \pm 2.50$ which give confirmation about the good flow properties of these formulae. These findings were further shored by Hausner ratio values. The Hausner ratio results of proniosomal formulae having span 20 and span 80 were found to be between $1.27 \pm 0.02$ and $1.46 \pm 0.05$ indicating poor flowability. On the other hand, proniosomal formulae containing span 40 and span 60 have values of Hausner ratios between $1.13 \pm 0.04$ and $1.24 \pm 0.04$ assuring good flow properties. Finally, it was noticed that proniosomal formulae containing span 40 and span 60 have good flow properties. However, those having span 40 and span 60 show poor flowability. This may be due to cohesivity of powders imparted by viscous liquid span 20 and span 80 .

\section{Preparation of niosomes from proniosomes and morphological} evaluation (Photomicroscopy)

The optical photographs of all reconstituted proniosomal formulae are shown in fig. (1-28). The photographs revealed that the formed niosomes are unilamellar vesicles with a spherical shape and smooth surface. The vesicles were insular and separate without aggregation or lumping. Apparently, proniosomal formulae containing span 40 and span 60 yielded vesicles of large numbers with well-identified outline and core which will affect the entrapment efficiency of loaded drug directly. However proniosomal formulae containing span 20 and span 80 produced small numbers of vesicles with a slightly different outline. This may be due to the high phase transition temperatures of both span 40 and span 60 which will cause the formation of a large number of stable niosomal vesicles. The phase transition temperatures for span 20, 40 and 60 are 16, 42 and $53{ }^{\circ} \mathrm{C}$; respectively, however, span 80 possess the lowest phase transition temperature at $12{ }^{\circ} \mathrm{C}$ [35]. This explains why proniosomal formulae containing span 20 and span 80 produce small numbers of vesicles upon hydration. 
Table 2: Micromeritic properties of all prepared proniosomal formulae

\begin{tabular}{|c|c|c|c|c|c|}
\hline Formula & Angle of repose* & Bulk density* (g/ml) & Tapped density* $(\mathrm{g} / \mathrm{ml})$ & Carr's index* (\%) & Hausner ratio* \\
\hline F1 & $41.87 \pm 1.50$ & $0.5043 \pm 0.01$ & $0.6250 \pm 0.01$ & $21.00 \pm 1.32$ & $1.27 \pm 0.02$ \\
\hline $\mathrm{F} 2$ & $36.89 \pm 1.17$ & $0.5130 \pm 0.01$ & $0.6452 \pm 0.03$ & $22.23 \pm 1.60$ & $1.29 \pm 0.03$ \\
\hline F3 & $39.82 \pm 1.18$ & $0.5043 \pm 0.02$ & $0.6897 \pm 0.01$ & $26.05 \pm 1.30$ & $1.35 \pm 0.02$ \\
\hline $\mathrm{F} 4$ & $36.20 \pm 0.57$ & $0.5311 \pm 0.01$ & $0.7407 \pm 0.02$ & $27.43 \pm 1.36$ & $1.38 \pm 0.03$ \\
\hline F5 & $36.87 \pm 0.60$ & $0.5173 \pm 0.01$ & $0.7143 \pm 0.01$ & $25.84 \pm 2.27$ & $1.35 \pm 0.04$ \\
\hline F6 & $33.99 \pm 0.52$ & $0.5043 \pm 0.01$ & $0.6897 \pm 0.01$ & $25.19 \pm 2.22$ & $1.34 \pm 0.04$ \\
\hline F7 & $32.02 \pm 0.81$ & $0.5218 \pm 0.01$ & $0.6897 \pm 0.01$ & $26.07 \pm 2.27$ & $1.35 \pm 0.04$ \\
\hline F8 & $28.43 \pm 1.30$ & $0.4919 \pm 0.02$ & $0.5714 \pm 0.01$ & $13.11 \pm 1.33$ & $1.15 \pm 0.02$ \\
\hline F9 & $28.20 \pm 0.97$ & $0.5043 \pm 0.01$ & $0.5882 \pm 0.01$ & $12.61 \pm 0.19$ & $1.14 \pm 0.01$ \\
\hline F10 & $27.17 \pm 1.01$ & $0.5000 \pm 0.01$ & $0.5882 \pm 0.02$ & $15.00 \pm 2.50$ & $1.18 \pm 0.03$ \\
\hline F11 & $26.21 \pm 0.86$ & $0.4959 \pm 0.01$ & $0.5714 \pm 0.01$ & $12.38 \pm 2.32$ & $1.14 \pm 0.03$ \\
\hline F12 & $27.77 \pm 0.62$ & $0.5085 \pm 0.01$ & $0.6061 \pm 0.01$ & $16.94 \pm 1.37$ & $1.20 \pm 0.02$ \\
\hline F13 & $25.13 \pm 0.80$ & $0.5130 \pm 0.02$ & $0.6452 \pm 0.01$ & $19.62 \pm 2.50$ & $1.24 \pm 0.04$ \\
\hline F14 & $26.01 \pm 0.55$ & $0.4959 \pm 0.01$ & $0.6061 \pm 0.02$ & $14.88 \pm 2.51$ & $1.18 \pm 0.03$ \\
\hline F15 & $26.39 \pm 0.86$ & $0.4959 \pm 0.01$ & $0.5882 \pm 0.01$ & $16.50 \pm 2.61$ & $1.20 \pm 0.04$ \\
\hline F16 & $27.16 \pm 0.60$ & $0.5043 \pm 0.01$ & $0.5882 \pm 0.01$ & $15.94 \pm 2.70$ & $1.19 \pm 0.04$ \\
\hline F17 & $25.12 \pm 0.59$ & $0.5173 \pm 0.01$ & $0.5714 \pm 0.01$ & $11.18 \pm 2.84$ & $1.13 \pm 0.04$ \\
\hline F18 & $28.20 \pm 0.97$ & $0.4959 \pm 0.01$ & $0.5714 \pm 0.01$ & $12.38 \pm 2.32$ & $1.14 \pm 0.03$ \\
\hline F19 & $25.87 \pm 1.36$ & $0.5002 \pm 0.01$ & $0.5882 \pm 0.02$ & $14.98 \pm 2.36$ & $1.18 \pm 0.03$ \\
\hline F20 & $24.79 \pm 0.76$ & $0.5130 \pm 0.01$ & $0.5714 \pm 0.01$ & $11.07 \pm 2.76$ & $1.13 \pm 0.03$ \\
\hline F21 & $26.21 \pm 0.86$ & $0.4919 \pm 0.01$ & $0.5882 \pm 0.01$ & $18.03 \pm 1.30$ & $1.22 \pm 0.02$ \\
\hline F22 & $39.08 \pm 1.76$ & $0.4959 \pm 0.01$ & $0.7143 \pm 0.02$ & $31.38 \pm 2.39$ & $1.46 \pm 0.05$ \\
\hline F23 & $39.42 \pm 0.66$ & $0.5130 \pm 0.01$ & $0.6897 \pm 0.01$ & $26.49 \pm 0.94$ & $1.36 \pm 0.02$ \\
\hline F24 & $37.58 \pm 1.07$ & $0.5043 \pm 0.01$ & $0.6897 \pm 0.03$ & $30.26 \pm 2.54$ & $1.44 \pm 0.05$ \\
\hline F25 & $34.02 \pm 1.38$ & $0.5173 \pm 0.01$ & $0.6897 \pm 0.01$ & $24.13 \pm 1.34$ & $1.32 \pm 0.02$ \\
\hline F26 & $36.54 \pm 1.01$ & $0.5000 \pm 0.01$ & $0.6667 \pm 0.01$ & $23.33 \pm 1.44$ & $1.30 \pm 0.02$ \\
\hline F27 & $34.92 \pm 1.07$ & $0.5085 \pm 0.01$ & $0.6250 \pm 0.02$ & $21.15 \pm 1.57$ & $1.27 \pm 0.06$ \\
\hline F28 & $35.25 \pm 1.44$ & $0.5218 \pm 0.01$ & $0.6897 \pm 0.01$ & $24.34 \pm 1.13$ & $1.32 \pm 0.02$ \\
\hline
\end{tabular}

${ }^{*}$ Results are expressed as mean \pm S. D, $\mathrm{n}=3$

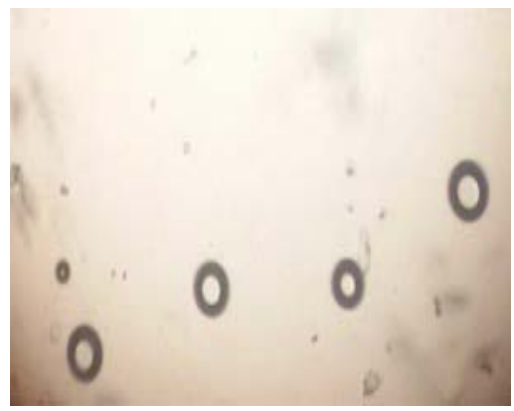

Fig. 1: Optical photograph of F1

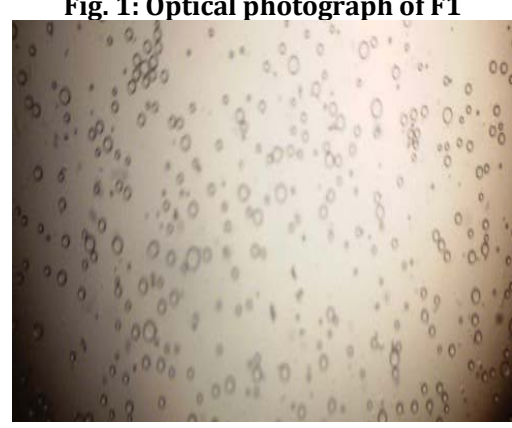

Fig. 4: Optical photograph of F4

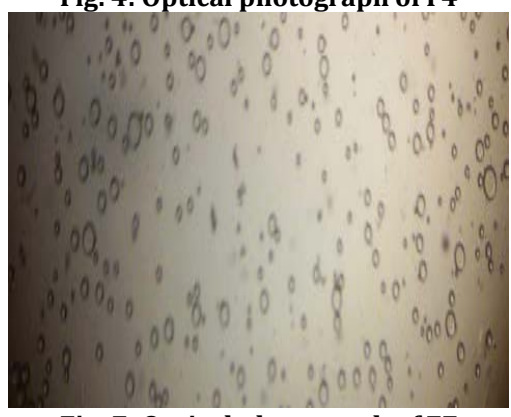

Fig. 7: Optical photograph of F7

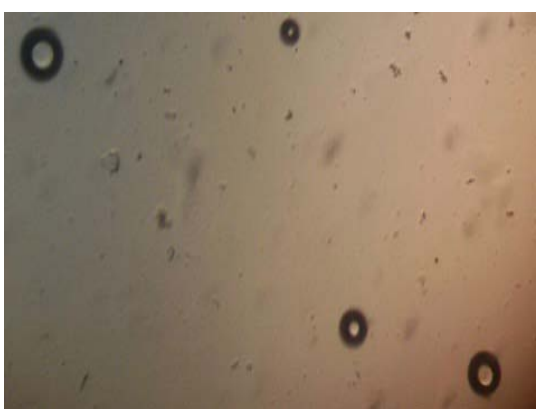

Fig. 2: Optical photograph of F2

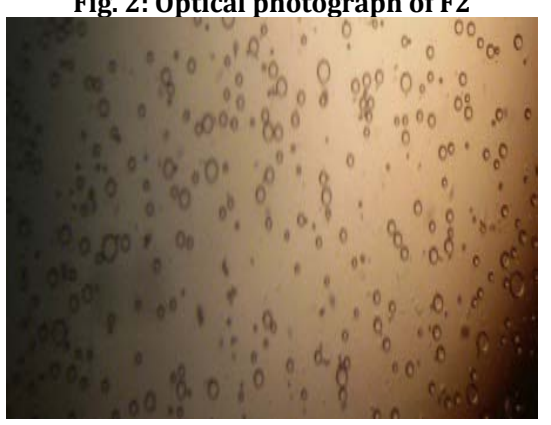

Fig. 5: Optical photograph of F5

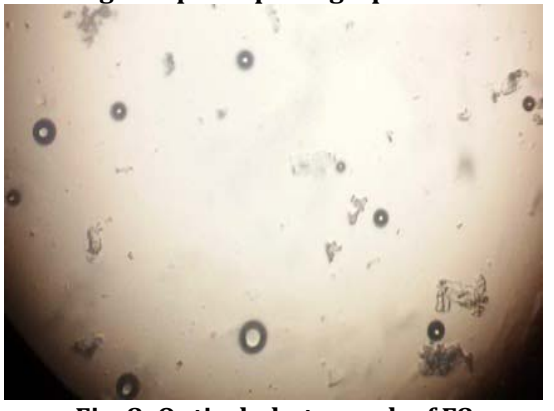

Fig. 8: Optical photograph of F8

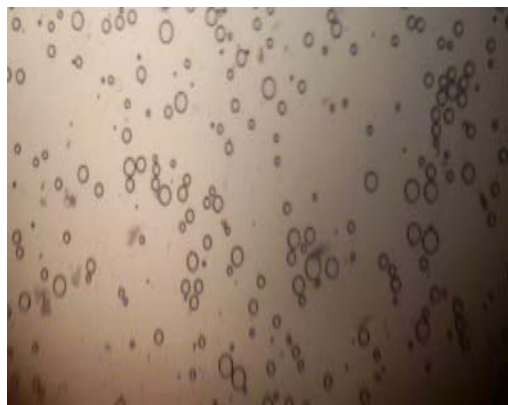

Fig. 3: Optical photograph of F3

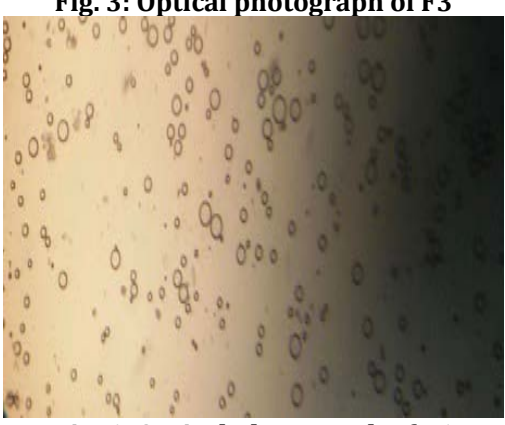

Fig. 6: Optical photograph of F6

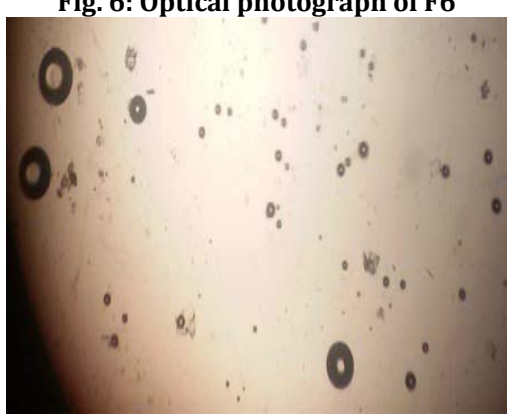

Fig. 9: Optical photograph of F9 


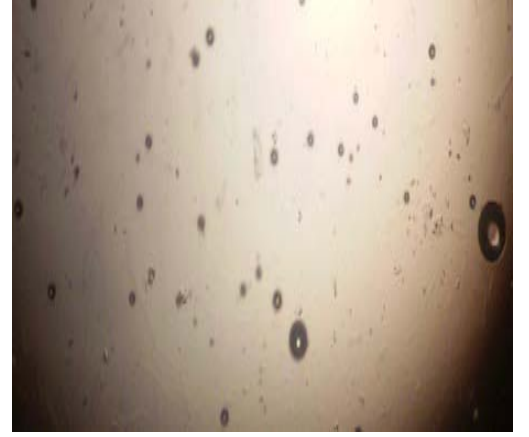

Fig. 10: Optical photograph of F10

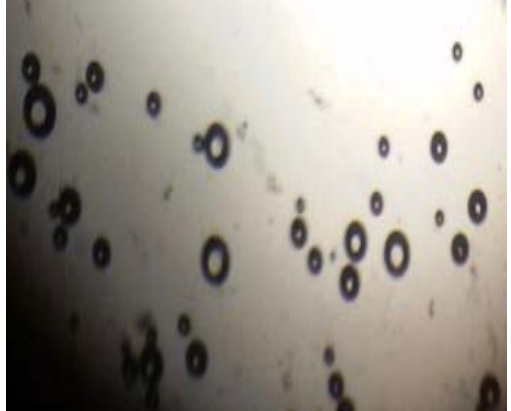

Fig. 13: Optical photograph of F13

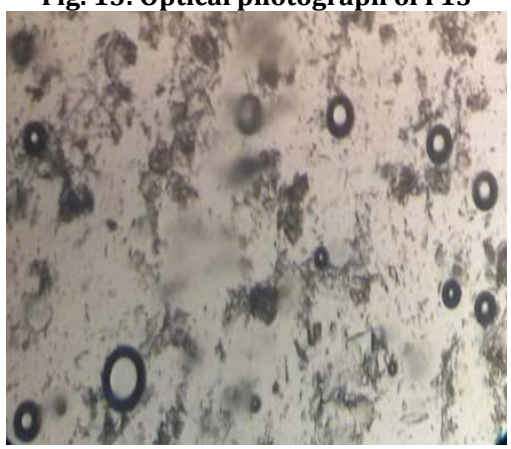

Fig. 16: Optical photograph of F16

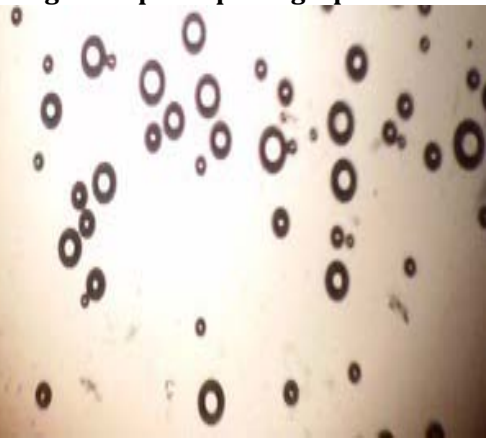

Fig. 19: Optical photograph of F19

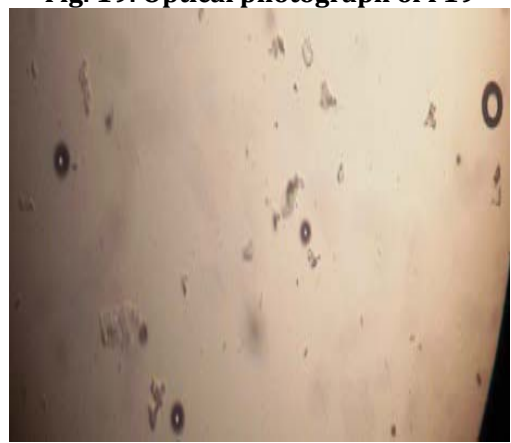

Fig. 22: Optical photograph of F22

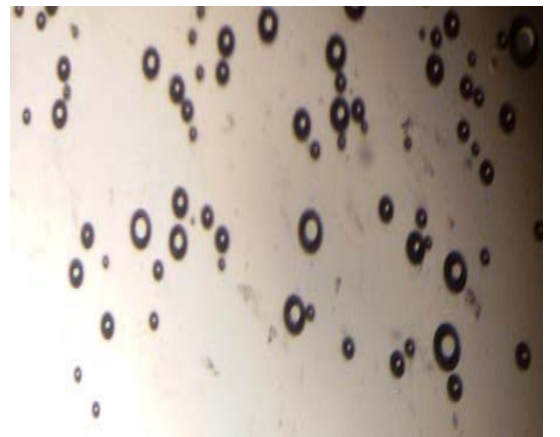

Fig. 11: Optical photograph of F11
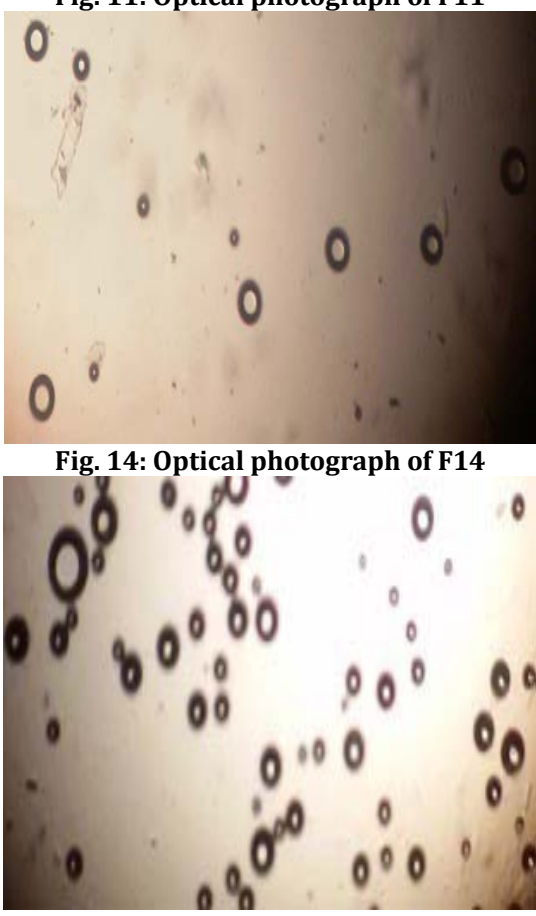

Fig. 17: Optical photograph of F17

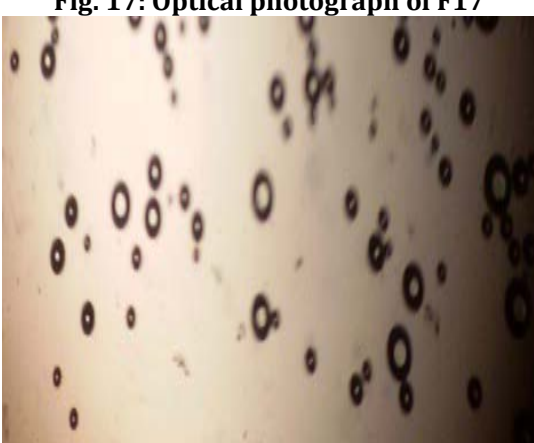

Fig. 20: Optical photograph of F20

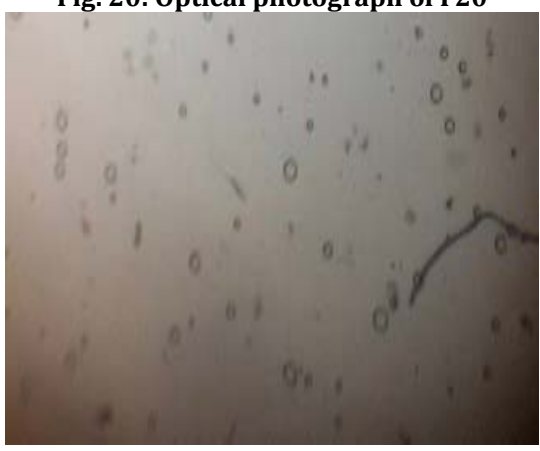

Fig. 23: Optical photograph of F23

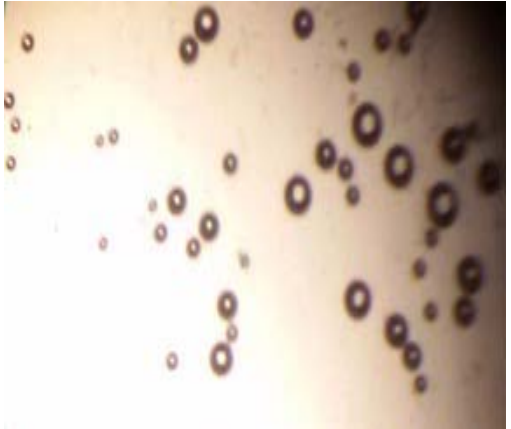

Fig. 12: Optical photograph of F12

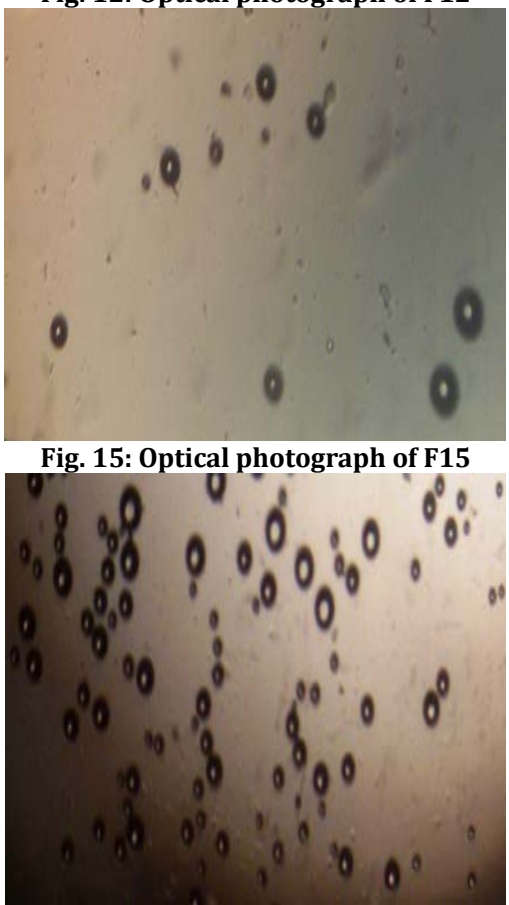

Fig. 18: Optical photograph of F18

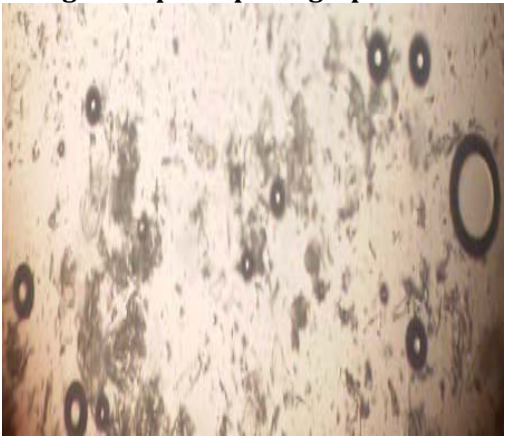

Fig. 21: Optical photograph of F21

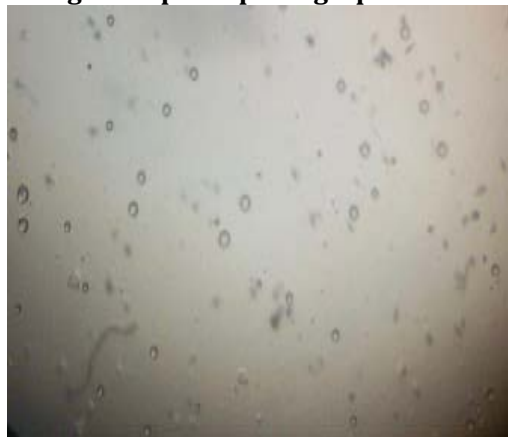

Fig. 24: Optical photograph of F24 


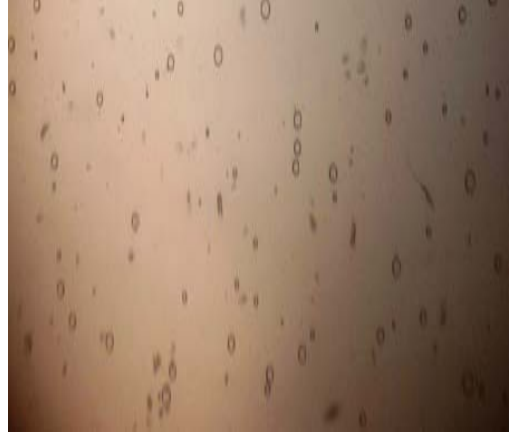

Fig. 25: Optical photograph of F25

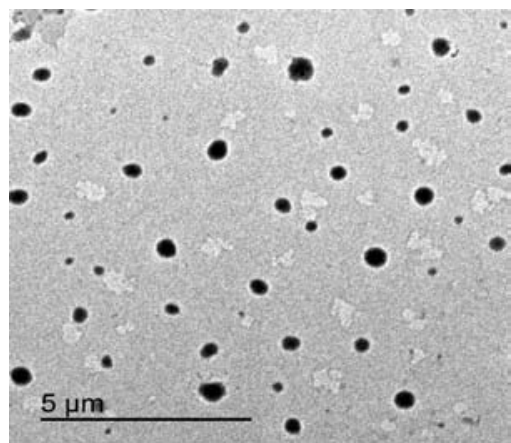

Fig. 29: TEM photograph of F1

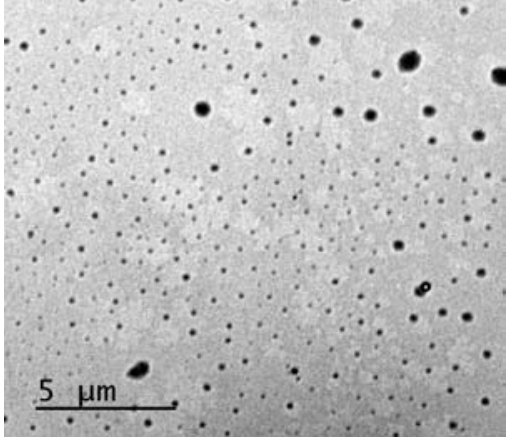

Fig. 32: TEM photograph of F4

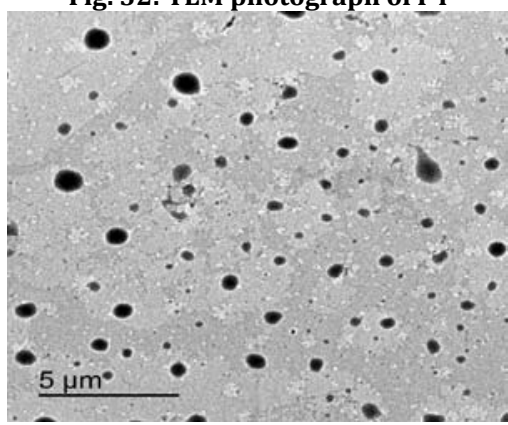

Fig. 35: TEM photograph of F7

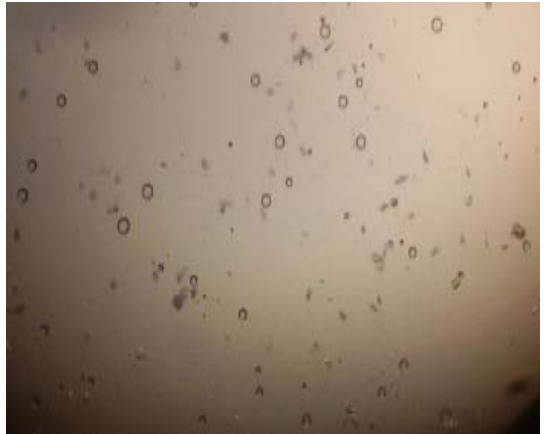

Fig. 26: Optical photograph of F26

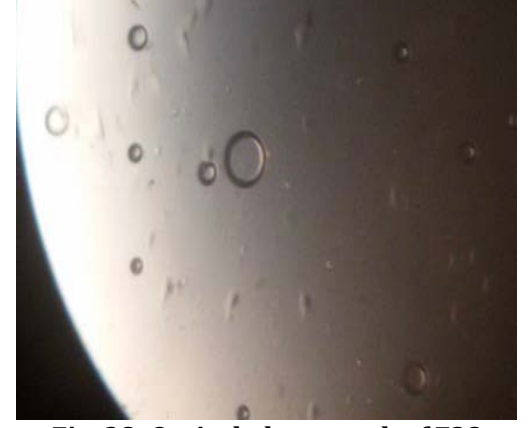

Fig. 28: Optical photograph of F28
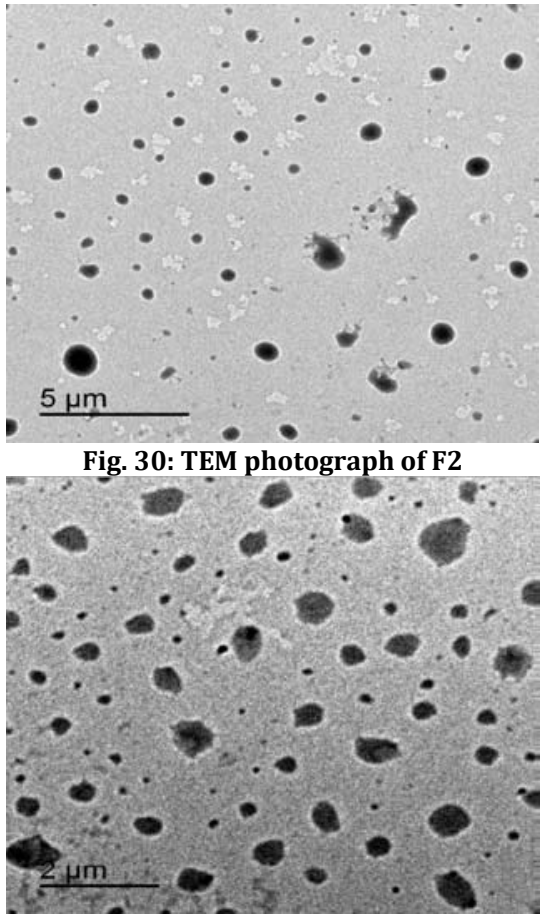

Fig. 33: TEM photograph of F5

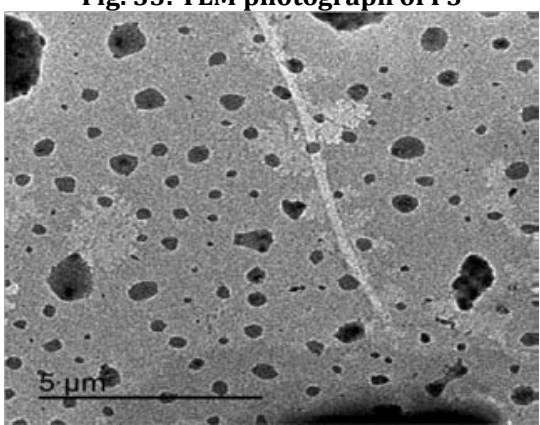

Fig. 36: TEM photograph of F8

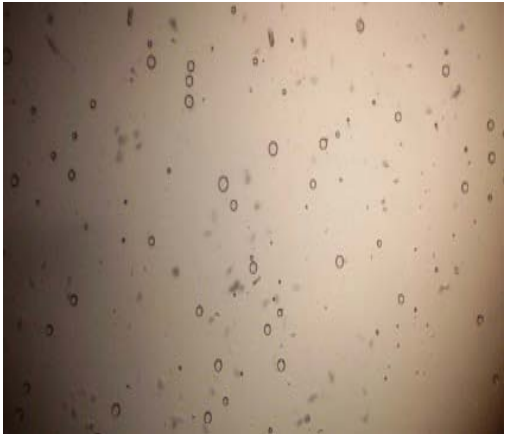

Fig. 27: Optical photograph of F27

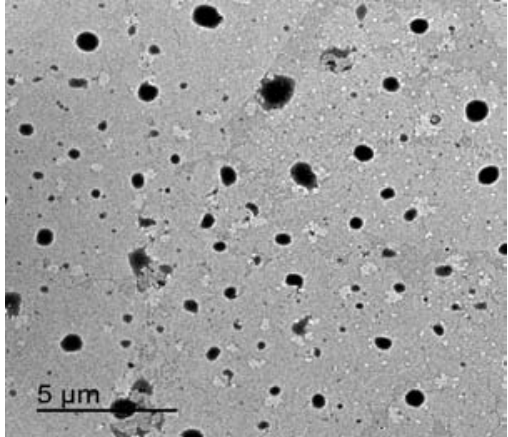

Fig. 31: TEM photograph of F3

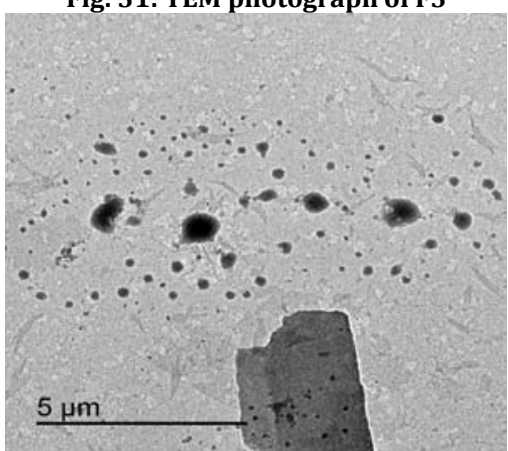

Fig. 34: TEM photograph of F6

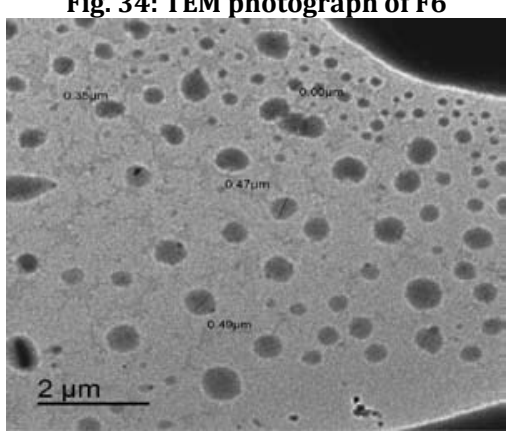

Fig. 37: TEM photograph of F9 


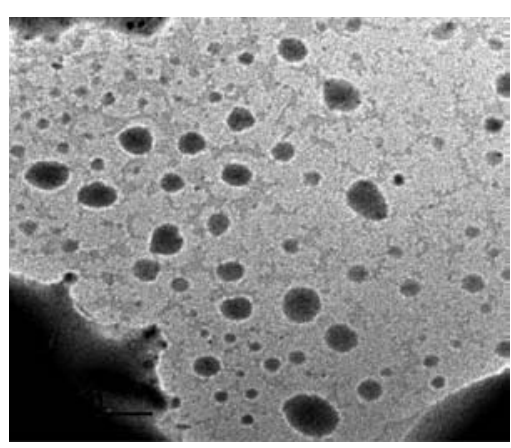

Fig. 38: TEM photograph of F10

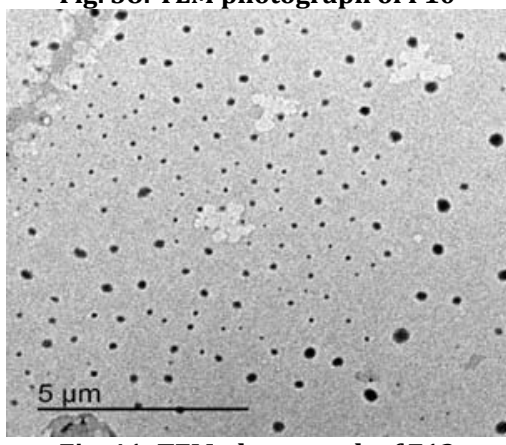

Fig. 41: TEM photograph of F13

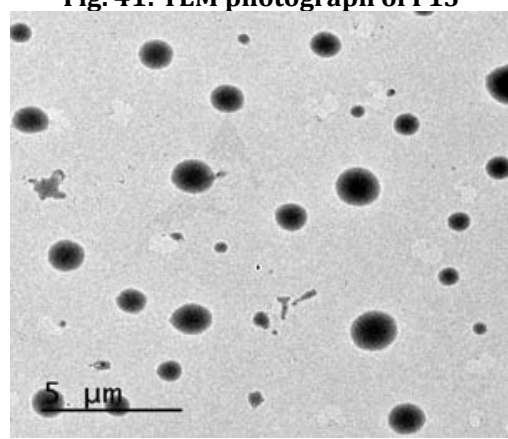

Fig. 44: TEM photograph of F16

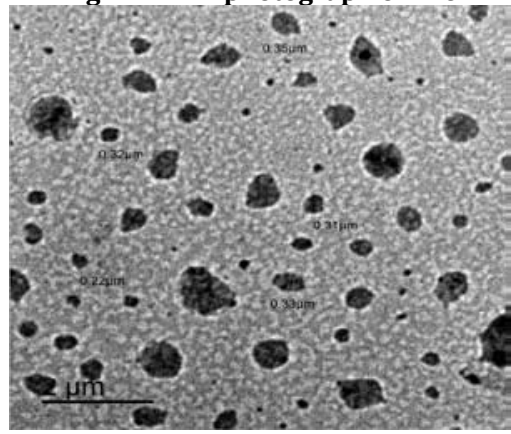

Fig. 47: TEM photograph of F19

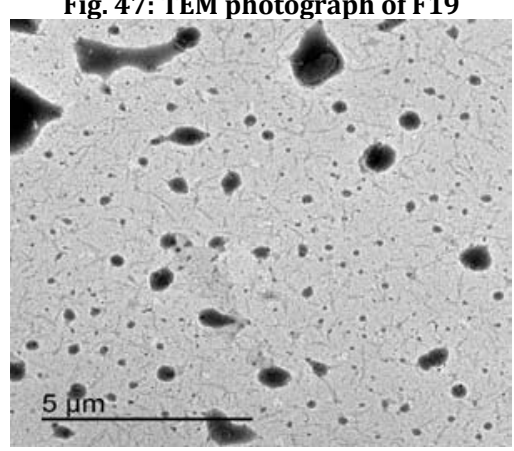

Fig. 50: TEM photograph of F22

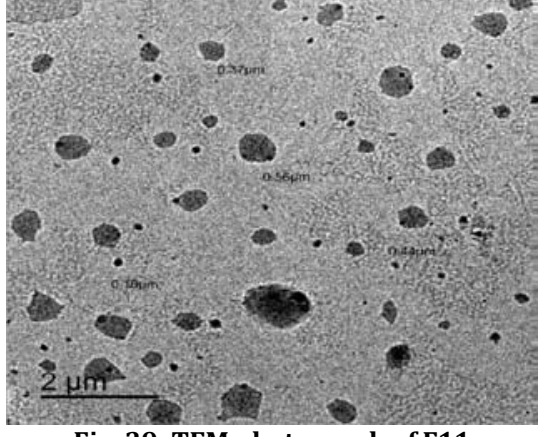

Fig. 39: TEM photograph of F11

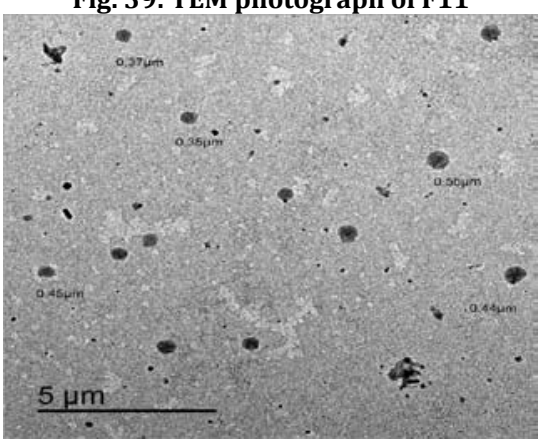

Fig. 42: TEM photograph of F14

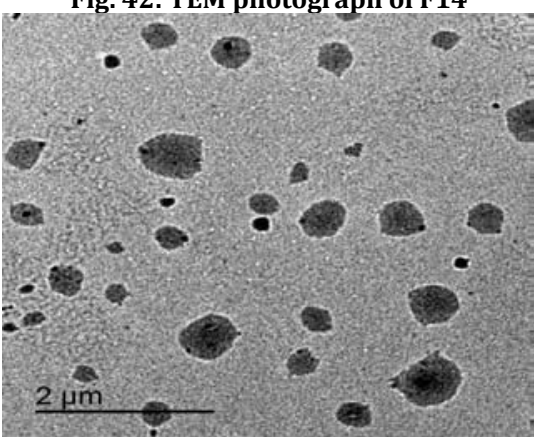

Fig. 45: TEM photograph of F17

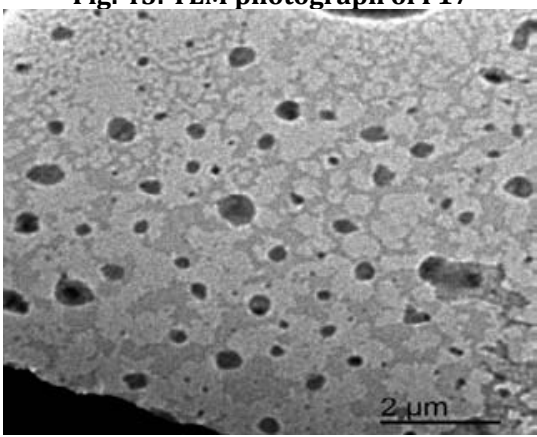

Fig. 48: TEM photograph of F20

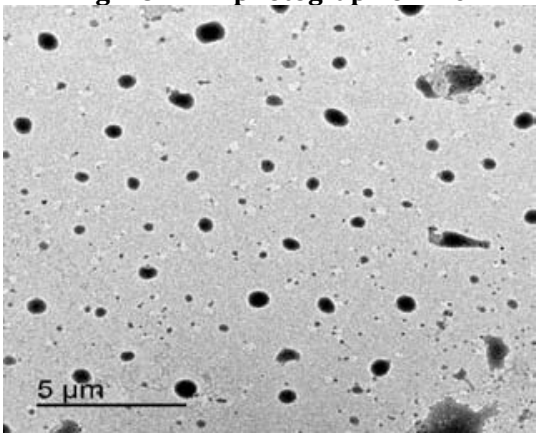

Fig. 51: TEM photograph of F23

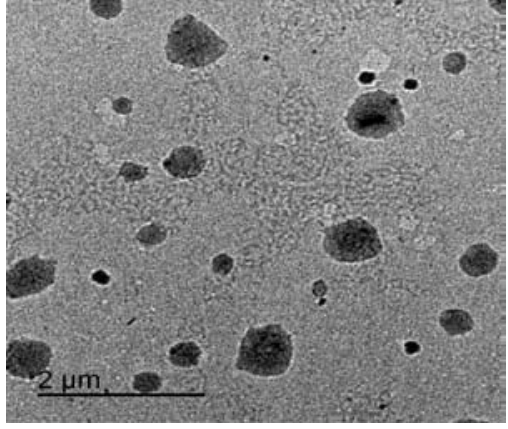

Fig. 40: TEM photograph of F12

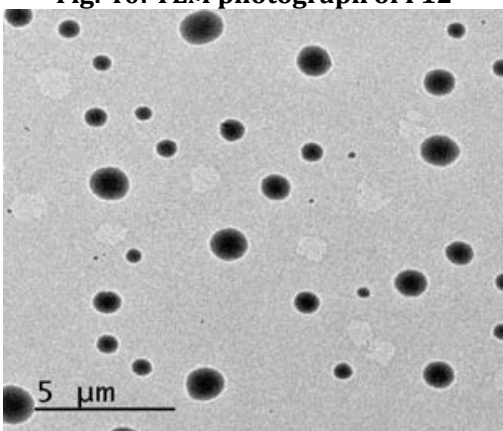

Fig. 43: TEM photograph of F15

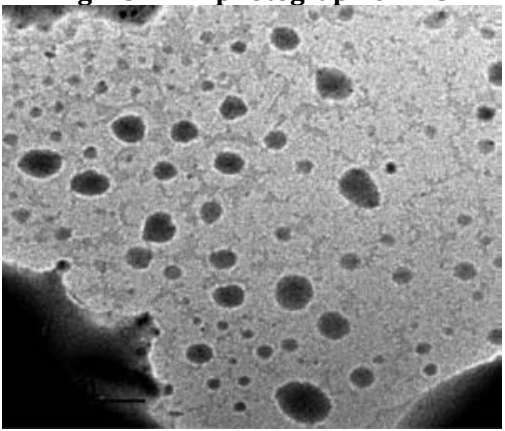

Fig. 46: TEM photograph of F18

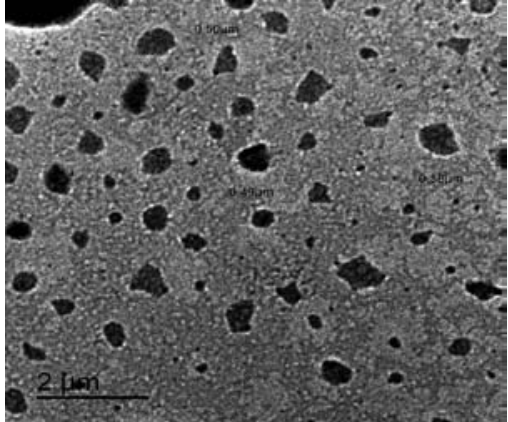

Fig. 49: TEM photograph of F21

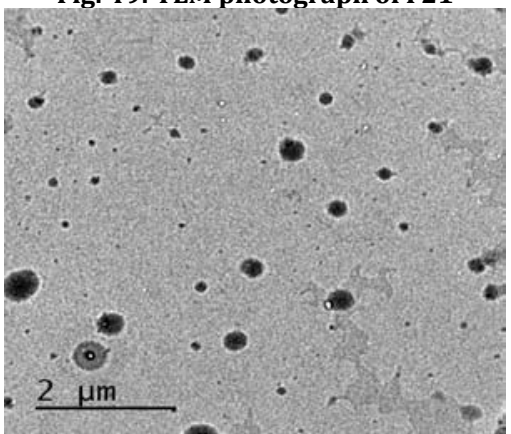

Fig. 52: TEM photograph of F24 


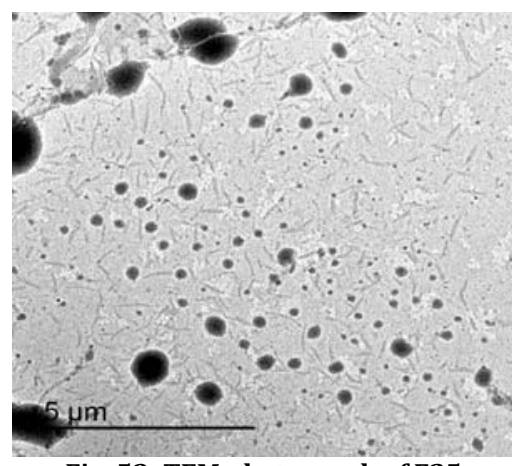

Fig. 53: TEM photograph of F25

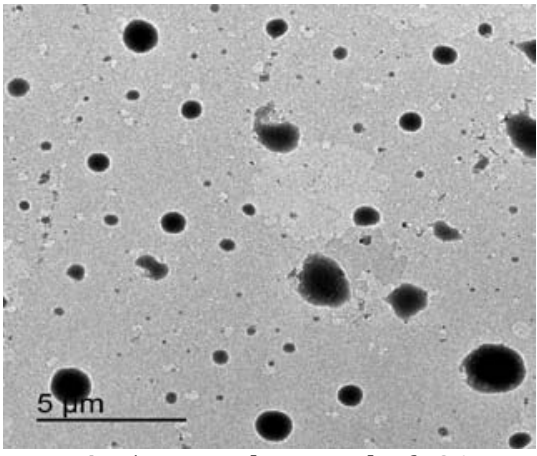

Fig. 54: TEM photograph of F26

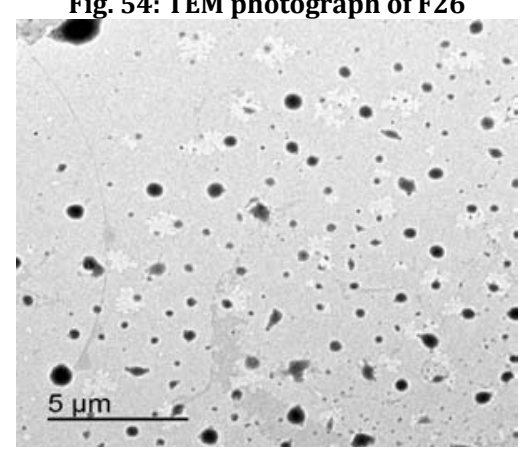

Fig. 56: TEM photograph of F28

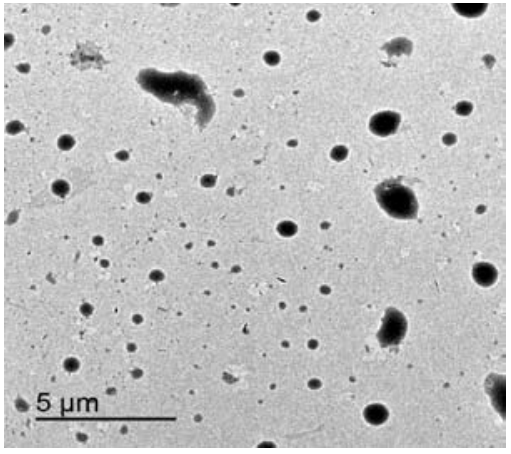

Fig. 55: TEM photograph of F27

\section{Morphological characterization using TEM}

Vesicles formation was further confirmed by TEM. The transmission electron microscopy photographs of the niosomes prepared from proniosomal formulae are shown in fig. (29-56). From the presented figures, it is apparent that the majority of the vesicles are well identified, nanosized and separate with sharp outermost bilayer boundaries having large internal space. The vesicles seem to be like a spherical reservoir and devoid of any surface artifacts.

\section{Analysis of the recorded TEM images}

Analysis of TEM photographs of all proniosomal formulae using the software Nano Measurer 1.2.5 revealed that the mean particle size of all prepared formulae ranged between $142.98 \mathrm{~nm}$ (F13) and $861.98 \mathrm{~nm}$ (F15) as presented in fig. (57-84). The discussion of particle size analysis results here is illogical as TEM images represent a very small section of the sample so full discussion of particle size analysis will be in the next test. We just took an overview about particle size distribution of all prepared formulae.

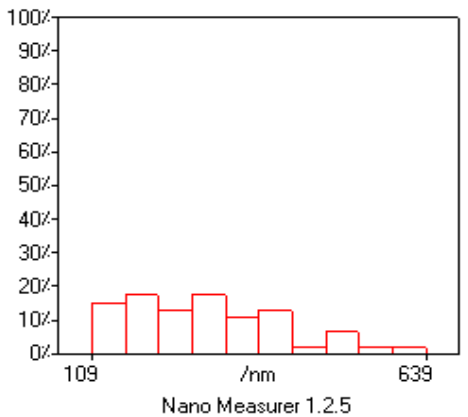

Fig. 57: Size distribution of F1

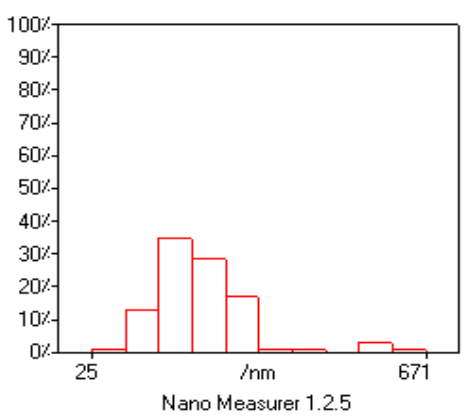

Fig. 60: Size distribution of F4

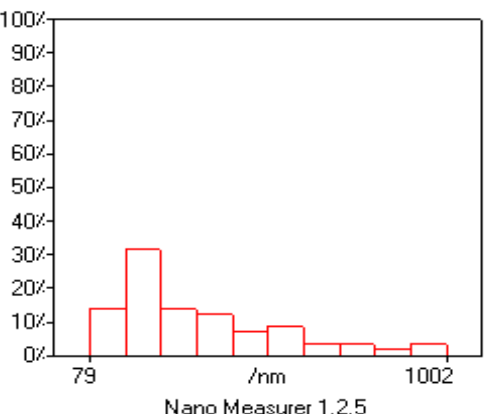

Fig. 58: Size distribution of F2

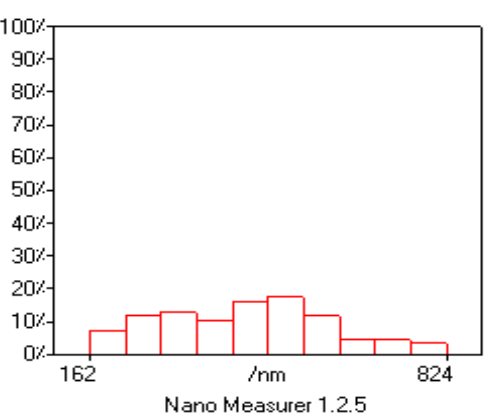

Fig. 61: Size distribution of F5

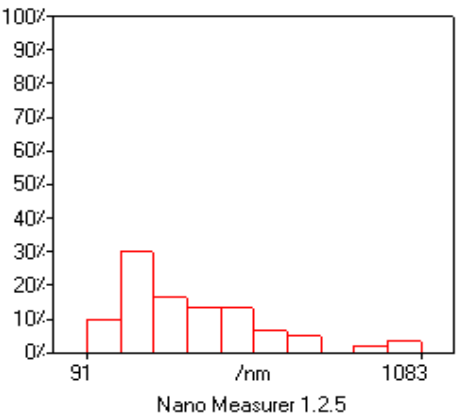

Fig. 59: Size distribution of F3

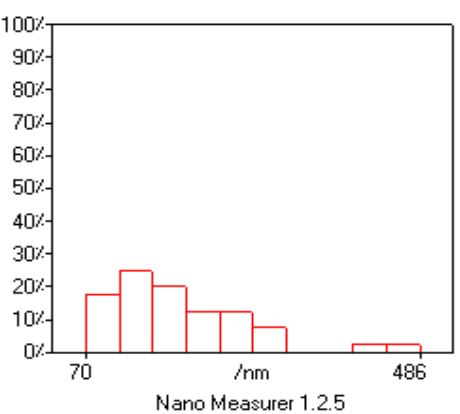

Fig. 62: Size distribution of F6 


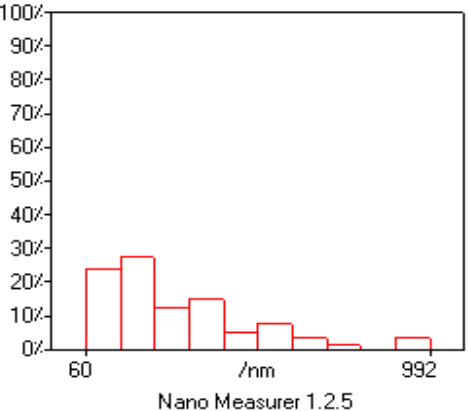

Fig. 63: Size distribution of F7

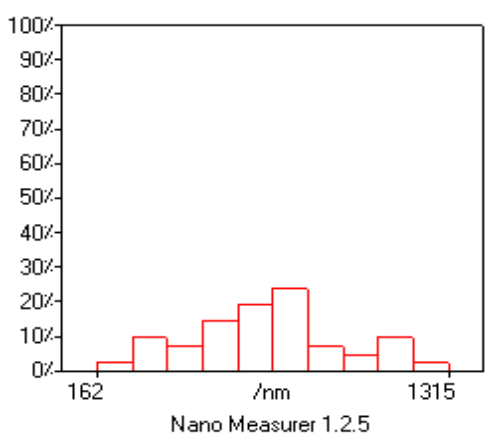

Fig. 66: Size distribution of F10

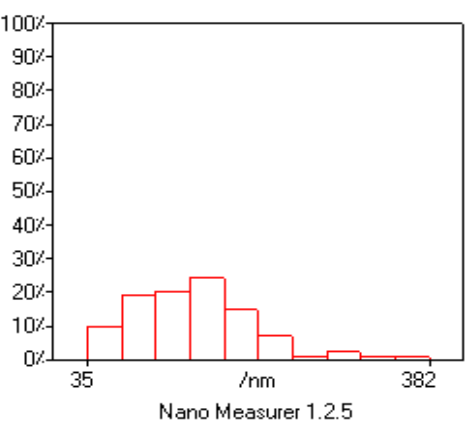

Fig. 69: Size distribution of F13

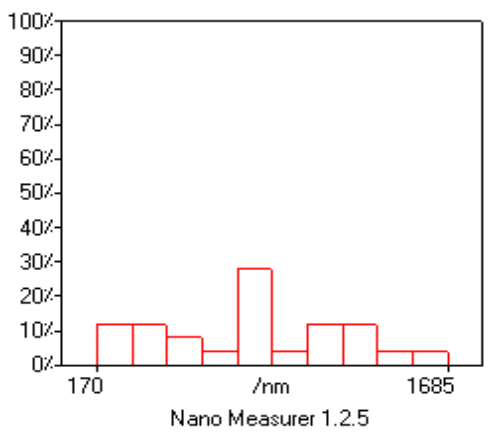

Fig. 72: Size distribution of F16

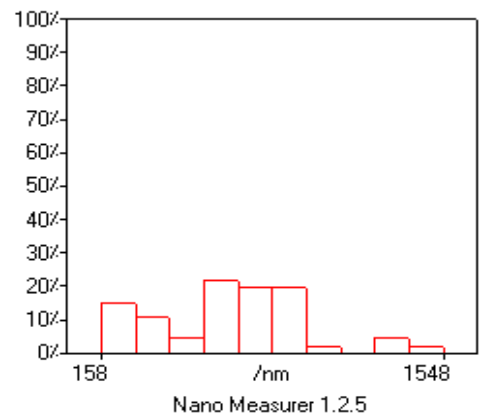

Fig. 75: Size distribution of F19

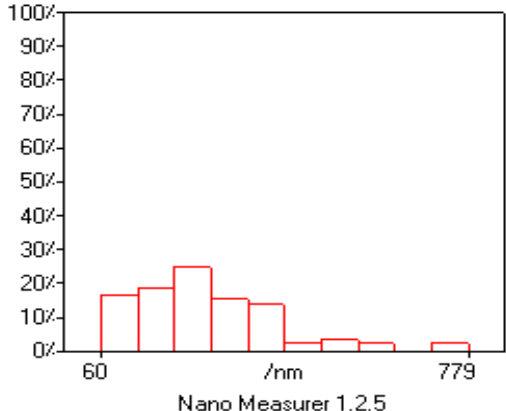

Fig. 64: Size distribution of F8

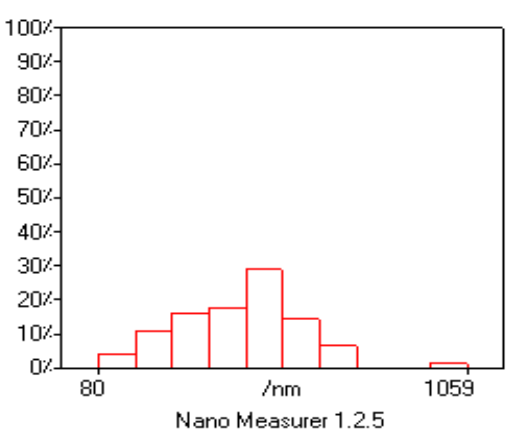

Fig. 67: Size distribution of F11

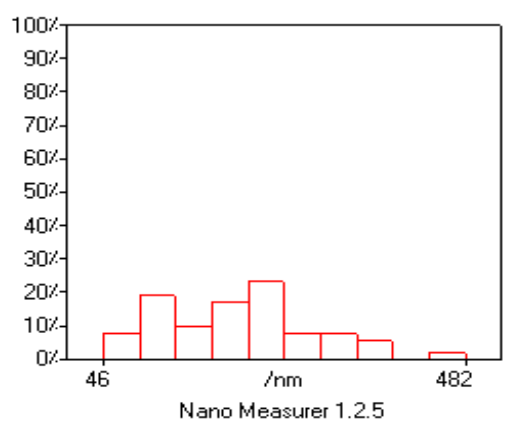

Fig. 70: Size distribution of F14

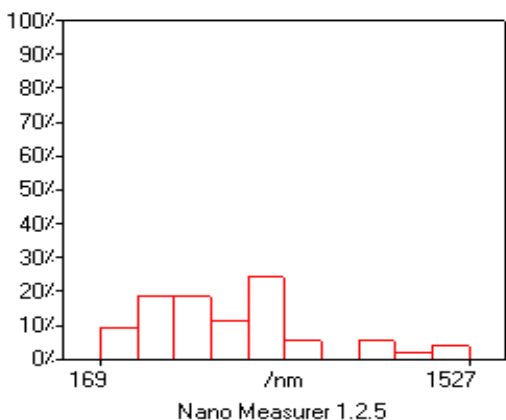

Fig. 73: Size distribution of F17

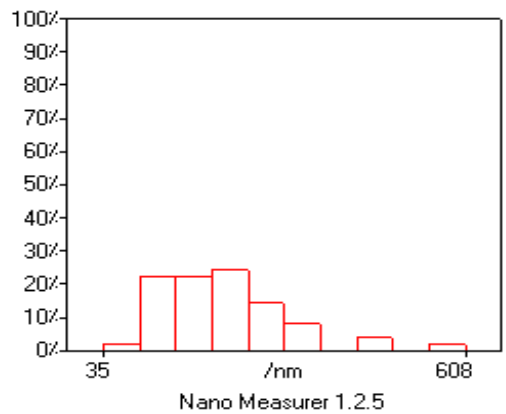

Fig. 76: Size distribution of F20

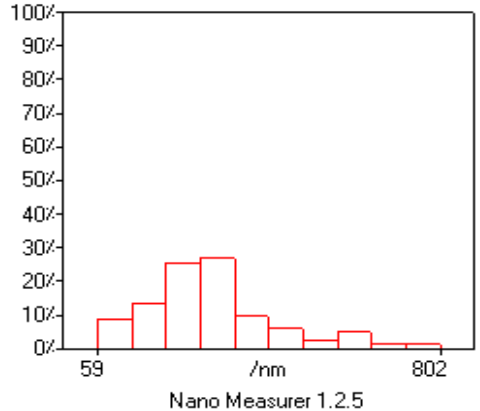

Fig. 65: Size distribution of F9

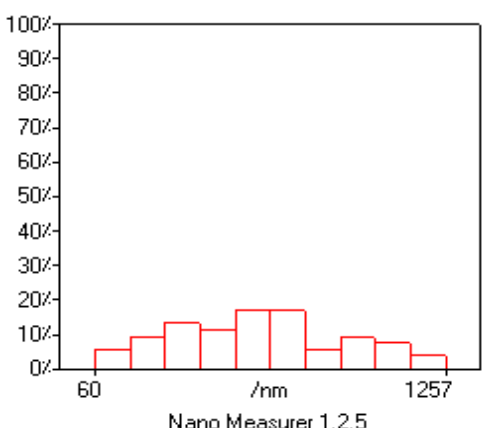

Fig. 68: Size distribution of F12

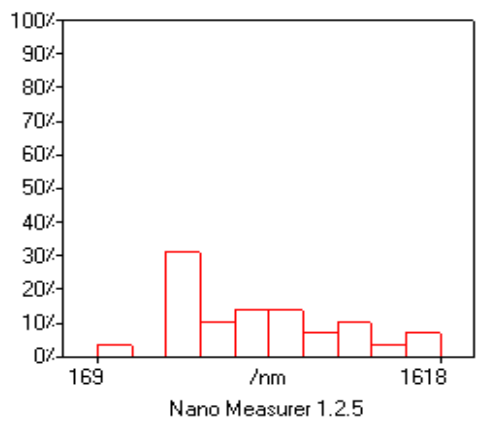

Fig. 71: Size distribution of F15

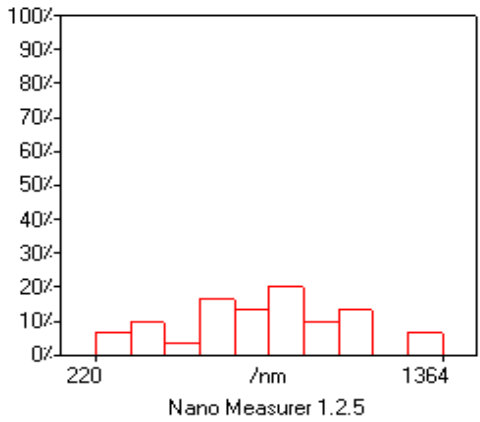

Fig. 74: Size distribution of F18

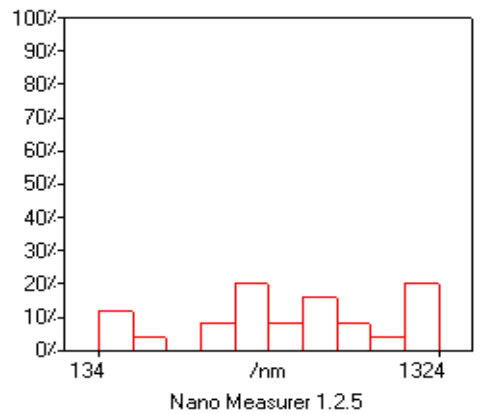

Fig. 77: Size distribution of F21 


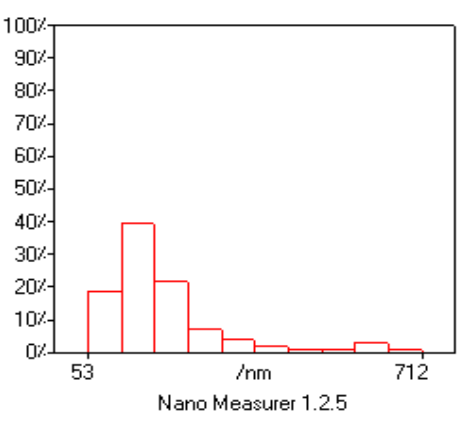

Fig. 78: Size distribution of F22

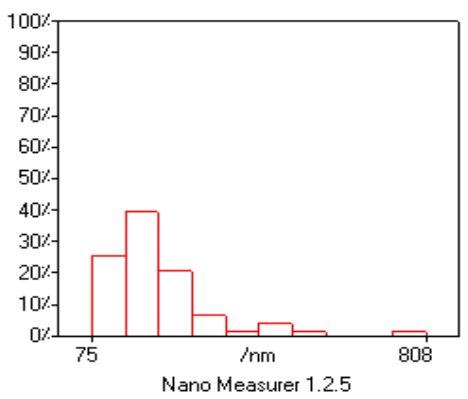

Fig. 81: Size distribution of F25

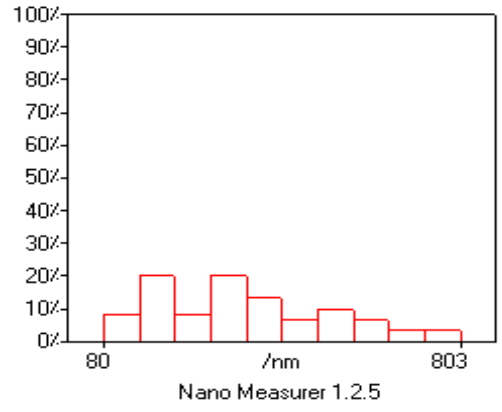

Fig. 79: Size distribution of F23

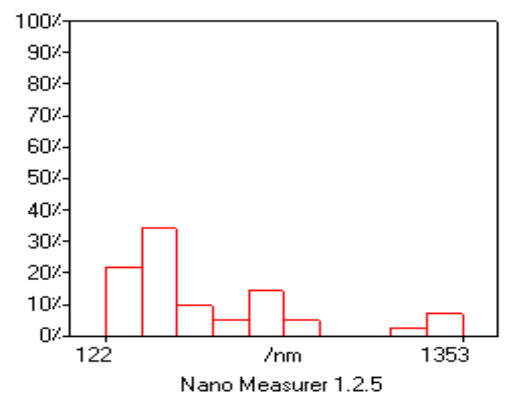

Fig. 82: Size distribution of F26

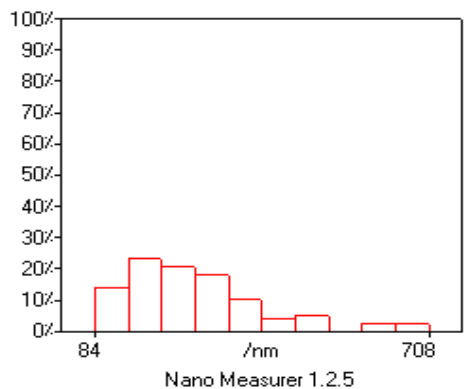

Fig. 84: Size distribution of F28

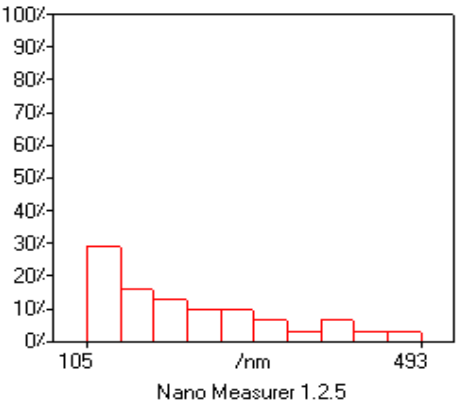

Fig. 80: Size distribution of F24

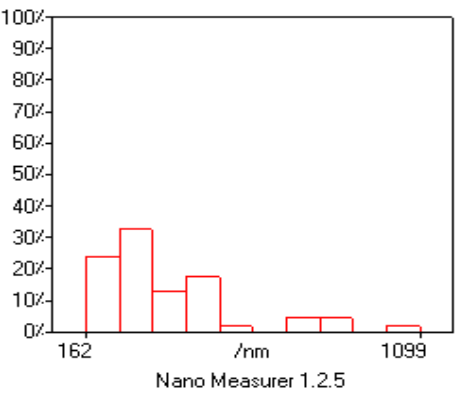

Fig. 83: Size distribution of F27

\section{Particle size analysis and PDI determination}

Vesicles size and particle size distribution are important parameters for the vesicular drug delivery systems. The particle size of the formed vesicles was in the nanometric dimensions ranging from $252.9 \pm 0.43 \mathrm{~nm}(\mathrm{~F} 4)$ to $624.3 \pm 0.23 \mathrm{~nm}$ (F28) as seen in the table (3). From the particle size analysis, it was clear that there are two factors affecting particle size which are surfactant type and cholesterol content. There was an increment in the vesicular size upon increasing the alkyl chain length of surfactant. The size of the vesicles increased gradually from span $20(252.9 \pm 0.43-357.2 \pm 0.56 \mathrm{~nm})<$ span $40(361.7 \pm 0.84-419.1 \pm 1.05 \mathrm{~nm})<\operatorname{span} 60(428.2 \pm 0.74-494.6 \pm 0.51$ $\mathrm{nm})<\operatorname{span} 80(512.4 \pm 0.47-624.3 \pm 0.23 \mathrm{~nm})$. This increment is linked to the alkyl chain length of span (C12-C18), which leads to elevated critical packing parameter thus the vesicle size increases [36]. It was also observed as the cholesterol concentration increased, an increase in the mean vesicle size occurred. This comes in accordance with the research done by Manconi et al. [37], who noted that, as the cholesterol surfactant ratio decreased in niosomal formulae, reduction in the vesicle size occur. The structure properties of cholesterol and its lipid solubility are the cause for its effect on the vesicle size. Cholestrol is loaded in hollow spaces between the surfactant molecules and expands the vesicles bilayers thus increased the particle size of vesicles [38]. It was also noticed that small sized vesicles with high surface charge values formed when the equal molar ratio of surfactant and cholesterol were used as presented in table (3). Our results also comply with the literature reports [39]. The mean particle size is not the only parameter to be considered in the formulation of proniosomes. The size distribution is another parameter of equal importance. The polydispersity index was calculated according to Bhavana et al. [40]. A polydispersity index of 1 indicates large variations in particle size; a reported value of 0 means that size variation is absent [41]. The obtained low PDI values of all proniosomes derived niosomes $(0.387 \pm 0.05-$ $0.835 \pm 0.03$ ) indicate a limited variation in particle size as reported in the table (3).

\section{Zeta potential determination}

Zeta potential predicts the stability of the carrier system. The higher the zeta potential value, the more repulsion between charged particles and hence the more stability against aggregation. Particles with zeta potential values more than $(+30 \mathrm{mV})$ or less than $(-30 \mathrm{mV})$ are considered stable [42]. The zeta potential values of all prepared proniosomal formulae are listed in table (3). The values ranged from between-18.3 \pm 0.56 to- $43.8 \pm 0.35 \mathrm{mV}$ which are high enough for electrostatic stabilization. Negative values of all prepared formulae indicate the formation of stable systems [43]. This higher charge on the vesicle surfaces produces a repulsion force which made them stable, devoid of aggregation and providing an evenly distributed dispersion. These results were in complete accordance with Litha et al. who prepared Clotrimazole based proniosomes, and found that zeta potential of the optimized formula was- $44.45 \mathrm{mV}$ [44].

\section{Stability studies}

Based upon the rank order employed for all proniosomal formulae depending on their characterization, two optimized proniosomal formulae were selected to be tested for stability study. From the particle size analysis, zeta potential and micromeritic properties, formulae F11 and F9 were chosen respectively as illustrated in table (4). The physical appearance, micromeritic properties, vesicle size and zeta potential were monitored for the optimized proniosomal 
powder formulae F9 and F11 upon storage at refrigerated and ambient room temperature for a period of $90 \mathrm{~d}$ as shown in the table (5). The results indicated that there was no appreciable change in physical appearance, flow characteristics and zeta potential when formulae F9 and F11 were stored at refrigerated and room temperatures. However, there was a slight increase in vesicle size of the prepared formulae. This increase was higher in formulae stored at room temperature than at refrigerated temperature indicating that prepared formulae were relatively stable at $4 \pm 1{ }^{\circ} \mathrm{C}$, as compared to $25{ }^{\circ} \mathrm{C} \pm 2$. The stability studies suggest that the proniosomal formulae were comparatively more stable when stored at refrigerated conditions compared to room temperature.

Table 3: Particle size, PDI and zeta potential of all prepared proniosomal formulae

\begin{tabular}{|c|c|c|c|}
\hline Formula & Particle size* (nm) & PDI* $^{*}$ & Zeta potential $^{*}(\mathrm{mV})$ \\
\hline F1 & $308.0 \pm 0.25$ & $0.387 \pm 0.05$ & $-40.4 \pm 0.87$ \\
\hline $\mathrm{F} 2$ & $298.8 \pm 0.74$ & $0.835 \pm 0.03$ & $-40.8 \pm 1.17$ \\
\hline F3 & $264.6 \pm 0.50$ & $0.505 \pm 0.08$ & $-41.2 \pm 0.45$ \\
\hline $\mathrm{F} 4$ & $252.9 \pm 0.43$ & $0.591 \pm 0.11$ & $-42.3 \pm 0.71$ \\
\hline F5 & $330.3 \pm 0.14$ & $0.432 \pm 0.19$ & $-39.0 \pm 0.09$ \\
\hline F6 & $357.2 \pm 0.56$ & $0.477 \pm 0.04$ & $-36.4 \pm 0.24$ \\
\hline F7 & $338.2 \pm 0.33$ & $0.596 \pm 0.02$ & $-28.4 \pm 0.17$ \\
\hline F8 & $366.8 \pm 0.61$ & $0.610 \pm 0.14$ & $-41.4 \pm 0.61$ \\
\hline F9 & $365.9 \pm 0.17$ & $0.411 \pm 0.02$ & $-43.8 \pm 0.35$ \\
\hline F10 & $361.7 \pm 0.84$ & $0.626 \pm 0.09$ & $-43.4 \pm 0.26$ \\
\hline F11 & $396.9 \pm 1.14$ & $0.431 \pm 0.06$ & $-41.4 \pm 0.44$ \\
\hline F12 & $410.4 \pm 0.27$ & $0.444 \pm 0.04$ & $-42.6 \pm 1.12$ \\
\hline F13 & $386.7 \pm 0.83$ & $0.678 \pm 0.05$ & $-39.0 \pm 0.28$ \\
\hline F14 & $419.1 \pm 1.05$ & $0.403 \pm 0.12$ & $-39.5 \pm 0.33$ \\
\hline F15 & $448.3 \pm 0.44$ & $0.433 \pm 0.07$ & $-30.3 \pm 0.49$ \\
\hline F16 & $433.9 \pm 0.65$ & $0.605 \pm 0.14$ & $-22.2 \pm 0.39$ \\
\hline F17 & $446.8 \pm 0.37$ & $0.410 \pm 0.16$ & $-38.4 \pm 0.75$ \\
\hline F18 & $428.2 \pm 0.74$ & $0.416 \pm 0.08$ & $-28.6 \pm 0.14$ \\
\hline F19 & $455.5 \pm 0.41$ & $0.460 \pm 0.06$ & $-24.3 \pm 0.42$ \\
\hline F20 & $494.6 \pm 0.58$ & $0.652 \pm 0.20$ & $-22.1 \pm 0.39$ \\
\hline F21 & $470.8 \pm 0.29$ & $0.409 \pm 0.04$ & $-23.1 \pm 1.04$ \\
\hline F22 & $512.4 \pm 0.47$ & $0.630 \pm 0.13$ & $-18.3 \pm 0.56$ \\
\hline F23 & $554.5 \pm 0.95$ & $0.469 \pm 0.07$ & $-24.6 \pm 0.27$ \\
\hline $\mathrm{F} 24$ & $541.8 \pm 0.71$ & $0.487 \pm 0.11$ & $-36.9 \pm 0.08$ \\
\hline F25 & $518.7 \pm 0.18$ & $0.478 \pm 0.08$ & $-22.0 \pm 0.15$ \\
\hline F26 & $558.7 \pm 0.53$ & $0.526 \pm 0.09$ & $-24.6 \pm 0.47$ \\
\hline F27 & $622.0 \pm 0.88$ & $0.540 \pm 0.14$ & $-23.1 \pm 1.09$ \\
\hline F28 & $624.3 \pm 0.23$ & $0.512 \pm 0.03$ & $-24.5 \pm 0.24$ \\
\hline
\end{tabular}

${ }^{*}$ Results are expressed as mean $\pm \mathrm{SD}, \mathrm{n}=3$

Table 4: Rank order of all proniosomal formulae according to particle size analysis, zeta potential and micromeritic properties

\begin{tabular}{|c|c|c|c|c|c|c|}
\hline Formula & $\begin{array}{l}\text { Particle } \\
\text { Size }\end{array}$ & $\begin{array}{l}\text { Zeta } \\
\text { potential }\end{array}$ & $\begin{array}{l}\text { Angle of } \\
\text { repose }\end{array}$ & $\begin{array}{l}\text { Hausner } \\
\text { ratio }\end{array}$ & Total rank order & $\begin{array}{l}\text { Conclusive rank } \\
\text { order }\end{array}$ \\
\hline F1 & 4 & 1 & 28 & 15 & 48 & 10 \\
\hline $\mathrm{F} 2$ & 3 & 9 & 23 & 17 & 52 & 12 \\
\hline F3 & 2 & 8 & 27 & 23 & 60 & 17 \\
\hline $\mathrm{F} 4$ & 1 & 5 & 20 & 26 & 52 & 12 \\
\hline F5 & 5 & 11 & 22 & 22 & 60 & 17 \\
\hline F6 & 7 & 15 & 16 & 21 & 59 & 16 \\
\hline F7 & 6 & 18 & 15 & 24 & 63 & 21 \\
\hline F8 & 10 & 6 & 14 & 6 & 36 & 5 \\
\hline F9 & 9 & 2 & 12 & 5 & 28 & 2 \\
\hline F10 & 8 & 3 & 10 & 8 & 29 & 3 \\
\hline F11 & 12 & 6 & 6 & 3 & 27 & 1 \\
\hline F12 & 13 & 4 & 11 & 12 & 40 & 8 \\
\hline F13 & 11 & 11 & 3 & 14 & 39 & 7 \\
\hline F14 & 14 & 10 & 5 & 7 & 36 & 5 \\
\hline F15 & 18 & 16 & 8 & 11 & 53 & 14 \\
\hline F16 & 16 & 25 & 9 & 10 & 60 & 17 \\
\hline F17 & 17 & 13 & 2 & 2 & 34 & 4 \\
\hline F18 & 15 & 17 & 12 & 3 & 47 & 9 \\
\hline F19 & 19 & 22 & 4 & 8 & 53 & 14 \\
\hline F20 & 21 & 26 & 1 & 1 & 49 & 11 \\
\hline F21 & 20 & 23 & 6 & 13 & 62 & 20 \\
\hline F22 & 22 & 28 & 25 & 28 & 103 & 28 \\
\hline F23 & 25 & 19 & 26 & 25 & 95 & 27 \\
\hline F24 & 24 & 14 & 24 & 27 & 89 & 26 \\
\hline F25 & 23 & 27 & 17 & 19 & 86 & 24 \\
\hline F26 & 26 & 19 & 21 & 18 & 84 & 22 \\
\hline $\mathrm{F} 27$ & 27 & 23 & 18 & 16 & 84 & 22 \\
\hline F28 & 28 & 21 & 19 & 20 & 88 & 25 \\
\hline
\end{tabular}


Table 5: Effect of storage on micromeritic properties, vesicle size and zeta potential of proniosomal formulae F9 and F11 at room and refrigeration temperatures

\begin{tabular}{|c|c|c|c|c|c|}
\hline & \multirow[t]{2}{*}{ Time (Day) } & \multicolumn{2}{|l|}{ F9 } & \multicolumn{2}{|l|}{ F11 } \\
\hline & & $4^{\circ} \mathrm{C}$ & $25^{\circ} \mathrm{C}$ & $4^{\circ} \mathrm{C}$ & $25^{\circ} \mathrm{C}$ \\
\hline Angle & 0 & $27.34 \pm 0.71$ & & $26.69 \pm 0.24$ & \\
\hline \multirow[t]{3}{*}{ of repose* } & 30 & $28.87 \pm 0.33$ & $27.11 \pm 0.58$ & $26.47 \pm 0.67$ & $27.18 \pm 0.89$ \\
\hline & 60 & $28.55 \pm 0.94$ & $28.68 \pm 0.24$ & $28.35 \pm 0.38$ & $30.87 \pm 0.08$ \\
\hline & 90 & $27.39 \pm 0.57$ & $30.22 \pm 0.84$ & $27.59 \pm 0.42$ & $32.15 \pm 0.14$ \\
\hline Carr's index* & 0 & $13.24 \pm 1.04$ & & $12.81 \pm 0.81$ & \\
\hline \multirow[t]{3}{*}{ (\%) } & 30 & $14.74 \pm 0.61$ & $13.87 \pm 1.29$ & $14.55 \pm 0.72$ & $13.31 \pm 0.48$ \\
\hline & 60 & $13.08 \pm 0.37$ & $15.49 \pm 0.78$ & $14.17 \pm 0.35$ & $15.94 \pm 0.15$ \\
\hline & 90 & $13.54 \pm 0.88$ & $17.32 \pm 0.26$ & $13.31 \pm 0.41$ & $16.28 \pm 1.14$ \\
\hline \multirow{4}{*}{ Hausner ratio* } & 0 & $1.20 \pm$ & & $1.19 \pm$ & \\
\hline & 30 & $1.21 \pm 0.06$ & $1.22 \pm 0.04$ & $1.22 \pm 0.02$ & $1.18 \pm 0.01$ \\
\hline & 60 & $1.14 \pm 0.09$ & $1.24 \pm 0.06$ & $1.18 \pm 0.05$ & $1.21 \pm 0.05$ \\
\hline & 90 & $1.18 \pm 0.02$ & $1.27 \pm 0.03$ & $1.17 \pm 0.01$ & $1.24 \pm 0.07$ \\
\hline Vesicle size* & 0 & $320.70 \pm 1.94$ & & $375.84 \pm 2.04$ & \\
\hline \multirow[t]{3}{*}{$(\mathrm{nm})$} & 30 & $335 \pm 1.23$ & $357 \pm 2.14$ & $394 \pm 1.22$ & $438 \pm 0.87$ \\
\hline & 60 & $327 \pm 0.84$ & $384 \pm 0.53$ & $405 \pm 2.37$ & $429 \pm 1.69$ \\
\hline & 90 & $348 \pm 1.57$ & $387 \pm 0.71$ & $416 \pm 1.90$ & $433 \pm 2.08$ \\
\hline \multirow{4}{*}{$\begin{array}{l}\text { Zeta potential* } \\
(\mathrm{mV})\end{array}$} & 0 & $-42.7 \pm 0.64$ & & $-40.1 \pm 1.23$ & \\
\hline & 30 & $-40.5 \pm 1.06$ & $-39.5 \pm 0.32$ & $-41.5 \pm 0.29$ & $-39.4 \pm 0.58$ \\
\hline & 60 & $-41.3 \pm 0.48$ & $-40.7 \pm 1.29$ & $-40.3 \pm 0.67$ & $-35.3 \pm 1.84$ \\
\hline & 90 & $-38.2 \pm 1.59$ & $-36.4 \pm 0.81$ & $-40.7 \pm 1.39$ & $-37.7 \pm 0.79$ \\
\hline
\end{tabular}

*Results are expressed as mean $\pm \mathrm{SD}, \mathrm{n}=3$

\section{CONCLUSION}

The unloaded prepared vesicular systems were found to fulfill the characteristics of proniosomes. They had a particle size in the nanometric range, negative high zeta potential values as well as good flow characters. The optimized proniosomal formula containing span 40 and cholesterol in equimolar ratio exhibited low size, high surface charge, and good flow properties. The obtained results offered evidence that spray-dried lactose based proniosomes are promising stable drug delivery carriers and ready to incorporate different poorly water-soluble drugs in order to improve their limited oral bioavailability.

\section{AUTHORS CONTRIBUTIONS}

All the author have contributed equally

\section{CONFLICTS OF INTERESTS}

The authors declare no conflict of interest

\section{REFERENCES}

1. Ghorab M, Elsayed M, Nasr A, Gad S. Effect of additives on in vitro release of the orodispersible dosage form. Int J Pharm Pharm Sci 2015;7:283-9.

2. Dizaj S, Vazifehasl Z, Salatin S, Adibkia K, Javadzadeh Y. Nanosizing of drugs: effect on dissolution rate. Res Pharm Sci 2015;10:95-108.

3. Bayindir Z, Yuksel N. Provesicles as novel drug delivery systems. Curr Pharm Biotechnol 2015;16:344-64.

4. Couvreur P, Fattal E, Andremont A. Liposomes and nanoparticles in the treatment of intracellular bacterial infections. Pharm Res 1991;8:1079-86.

5. Schreier H, Bouwstra J. Liposomes, and niosomes as topical drug carriers: dermal and transdermal drug delivery. J Controlled Release 1994;30:1-15.

6. Gannu P, Pojaku R. Nonionic surfactant vesicular systems for effective drug delivery-an overview. Acta Pharm Sin B 2011;1:208-19.

7. Krishnagopal D, Alpana R. Niosome as a novel drug delivery system-a review. Int J Appl Pharm 2013;6:1-7.

8. Sunil K, Pushpendra K, Nalini P, Gyanendra Saxena. Comparative study of proniosomal drug delivery system of flurbiprofen. J Chem Pharm Res 2016;8:222-8.

9. Ye J, Jingyuan W, Sanjay G, Da L, Yulin Z, Lirong T, et al. Development of a novel niosomal system for oral delivery of Ginkgo biloba extract. Int J Nanomed 2013;8:421-30.
10. Peeyush V, Alpana R. Non-ionic provesicular drug carrier: an overview. Asian J Pharm Clin Res 2013;6:38-42.

11. Karim M, Asim S, Nikhil B, Arijit G, Sugata C, Mamata Behera, et al. Niosome: a future of targeted drug delivery systems. J Adv Pharm Technol Res 2010;1:374-80.

12. Zerrin S, Nilufer Y. Investigation of formulation variables and excipient Interaction on the production of Niosomes. AAPS PharmSciTech 2012;13:826-35.

13. Okore V, Attama A, Ofokansi K, Esimone C, Onuigbo E. Formulation and evaluation of Niosomes. Indian J Pharm Sci 2011;73:323-8.

14. Radha G, Sudha R, Sarvani B. A review on proniosomal drug delivery system for targeted drug action. J Basic Clin Pharm 2013;4:42-8

15. Abd-Elbary A, El-laithy H,Tadros M. Sucrose stearate-based proniosome-derived niosomes for the nebulisable delivery of cromolyn sodium. Int J Pharm 2008;357:189-98.

16. Almira I, David G. Maltodextrin-based proniosomes. AAPS PharmSci 2001;3:1-8.

17. Vajihe A, Daryoush A, Abbas P, Hojjat S. Release studies on ciprofloxacin loaded non-ionic surfactant vesicles. Avicenna J Med Biotechnol 2015;7:69-75.

18. Gurrapu A, Jukanti R, Reddy S, Kanuganti S, Jeevana J. Improved oral delivery of valsartan from maltodextrin based proniosome powders. Adv Powder Technol 2012;3:583-90.

19. Jigar V, Puja V, Krutika S. Formulation and evaluation of topical niosomal gel of erythromycin. Int J Pharm Pharm Sci 2011;3:123-6.

20. Tank C, Borkhataria C, Baria A. Formulation and evaluation of aceclofenac loaded maltodextrin based proniosomes. Int J ChemTech Res 2009;1:567-73.

21. Sajeev C, Vinay G, Archna R, Saha R. Oral controlled release formulation of diclofenac sodium by microencapsulation with ethylcellulose. J Microencap 2002;19:753-60.

22. Bhagwat A, D`Souza I. Formulation and evaluation of solid SMEDDS using aerosil 200 as solid carrier. Int Curr Pharm J 2012;12:414-9.

23. Surender R, Mahalaxmi R, Srinivas P, Deepak K, Kumar A, Sneh P. Self-emulsifying systems of Aceclofenac by extrusion/Spheronization: formulation and evaluation. J Chem Pharm Res 2011;3:280-9.

24. Veerareddy P, Bobbala S. Enhanced oral bioavailability of isradipine via proniosomal systems. Drug Dev Ind Pharm 2013;39:909-17.

25. Dalia S, Mohamed N, Mirhan M. Bioavailability and hypocholesterolemic effect of proniosomal simvastatin for transdermal delivery. Int J Pharm Pharm Sci 2013;5:344-51.

26. Preethy C, Boby J, Noby T, Praveen R, Jeny S, Betty C. Formulation and characterization of maltodextrin based 
proniosomes of cephalosporins. World J Pharm Sci 2015;3:62 74.

27. Nasr A, Gardouh A, Ghonaim H, Abdelghany E, Ghorab M. Effect of oils, surfactants and cosurfactant on phase behavior and physicochemical properties of self-nanoemulsifying drug delivery system (SNEDDS) for irbesartan and olmesartan. Int J Appl Pharm 2016;8:13-24.

28. Bitao F, Shujun C, Qiufang Y, Qingfeng S, Chunde J. Fabrication of cellulose nanofiber/AlOOH aerogel for flame retardant and thermal insulation. Materials 2017;10:1-10.

29. Mehanna M, Elmaradny H, Samaha M. Mucoadhesive liposomes as ocular delivery system: physical, microbiological, and in vivo assessment. Drug Dev Ind Pharm 2010;36:108-18.

30. Meenakshi K, Parvat K, Ashwani S, Divya D, Mayank K, Nidhi S. Formulation, characterization and in vitro evaluation of tactically engineered proniosomes for successful oral delivery of ramipril. Pharm Lett 2015;7:93-7.

31. Jadon P, Gajbhiye V, Jadon R. Enhanced oral bioavailability of griseofulvin via niosomes. AAPS PharmSciTech 2009;10:1186-92.

32. Hao Y, Zhao F, Li N, Yang Y. Studies on a high encapsulation of colchicine by niosome system. Int J Pharm 2002;244:73-80.

33. Bhowmik D, Chiranjib B, Krishnakanth S, Pankaj R, Chandira M. Fast dissolving tablet. J Chem Pharm Res 2009;1:163-77.

34. Sahoo S, Mallick A, Barik B, Senapati P. Preparation and in vitro evaluation of ethylcellulose microspheres containing stavudine by the double emulsion method. Die Pharmazie 2007;62:117-21.

35. Somayeh T, Jaleh V. Effect of different types of surfactants on the physical properties and stability of carvedilol nanoniosomes. Adv Biomed Res 2016;5:1-6.
36. Uchegbu I, Florence A. Non-ionic surfactant vesicles (niosomes): physical and pharmaceutical chemistry. Adv Colloid Interface Sci 1995;58:1-55.

37. Manconi M, Sinico C, Valenti D, Fadda A. Niosomes as carriers for tretinoin. I. preparation and properties. Int J Pharm 2002;234:237-48

38. Al-Muhammed J, Ozer A, Ercan M, Hincal A. In vivo studies on dexamethasone sodium phosphate liposomes. J Microencapsul 1996;13:293-306

39. Gopinath D, Ravi D, Rao B, Apte S, Renuka D, Rambhau D. Ascorbyl palmitate vesicles (Aspasomes): formation, characterization and applications. Int J Pharm 2004;271:95113.

40. Bhavana V, Ajay J, Jain N. Proniosome based transdermal delivery of levonorgestrel for effective contraception. J Controlled Release 1998;54:149-65.

41. Raymond M, Josbert M, Marcel H, Adrienne P, Grietje M, Gert S. Liposome-encapsulated prednisolone phosphate inhibits growth of established tumors in mice. Neoplasia 2005;7:11827.

42. Hanaor D, Michelazzi M, Leonelli C, Sorrell C. The effects of carboxylic acids on the aqueous dispersion and electrophoretic deposition of $\mathrm{ZrO}_{2}$. J Eur Ceram Soc 2012;32:235-44.

43. Rai S, Yasir M. Preparation, optimization and in vitro evaluation of cinnarizine loaded lipid based system. IOSR J Pharm 2012;2:47-56

44. Litha T, Vidya V. Formulation and optimization of clotrimazole loaded proniosomal gel using $3^{2}$ factorial design. Sci Pharm 2012;80:731-48. 